\title{
Dynamic Capital Structure Adjustment and the Impact of Fractional Dependent Variables
}

\author{
Ralf Elsas and David Florysiak*
}

\begin{abstract}
Researchers in empirical corporate finance often use bounded ratios (e.g., debt ratios) as dependent variables in their regressions. Using the example of estimating the speed of adjustment toward target leverage, we show by Monte Carlo and resampling experiments that commonly applied estimators yield severely biased estimates, as they ignore that debt ratios are fractional (i.e., bounded between 0 and 1). We propose a new unbiased estimator for adjustment speed in the presence of fractional dependent variables that also controls for unobserved heterogeneity and unbalanced panel data. This new estimator is suitable for corporate finance applications beyond capital structure research.
\end{abstract}

\section{Introduction}

In empirical corporate finance, many variables of interest are ratios that are fractional. Their values are economically restricted to lie in a certain interval, often between 0 and 1. Cash-to-assets, share repurchase, or debt-to-capital ratios are prominent examples. Estimating a regression model in which the dependent variable is a fraction bounded by 0 and 1 requires econometric methods that account for this fractionality, ${ }^{1}$ since standard estimators, such as ordinary least squares (OLS), assume that the dependent variable can take on every

\footnotetext{
*Elsas, elsas@bwl.lmu.de, Florysiak (corresponding author), florysiak@bwl.lmu.de, Ludwig Maximilian University of Munich, Faculty of Business Administration (Munich School of Management), Munich 80539, Germany. We thank Nikolas Breitkopf, Markus Franke, Rongbing Huang (a referee), Peter Iliev, Paul Malatesta (the editor), Daniel Rettl, Martin Spindler, Alex Stomper, Ivo Welch, and two anonymous referees, and especially Mark Flannery and Vidhan Goyal for helpful comments. We are particularly grateful to Catharina Klepsch and Verena Jäger for incredible research assistance. We have benefited from comments from seminar participants at the WHUOtto Beisheim School of Management in Vallendar, 2009 Hong Kong University of Science and Technology Finance PhD Workshop, 2010 Midwest Finance Association Annual Meeting in Las Vegas, 2010 Annual Conference of the Swiss Society for Financial Market Research in Zurich, 2010 Eastern Finance Association Annual Meeting in Miami Beach, 2010 European Financial Management Association Annual Meeting in Aarhus, 2010 German Finance Association Annual Meeting in Hamburg, 2011 Campus for Finance Conference in Vallendar, and 2011 Financial Management Association Annual Meeting in Denver. This paper builds on a chapter of Florysiak's 2011 University of Munich doctoral dissertation. Part of this research was conducted while Florysiak was visiting the Hong Kong University of Science and Technology and the UCLA Anderson School of Management.

${ }^{1}$ Using the word "fractional" to describe a variable bounded by 0 and 1 is imprecise because fractions need not be bounded and can be outside the unit interval. Nevertheless, to maintain the
} 
negative or positive real number. The consequences of ignoring fractionality may be biased estimation and inference, potentially leading to flawed economic conclusions.

The magnitude of the potential bias from ignoring fractionality very often depends on the research question, the econometric model to be estimated, and the nature of the data. To illustrate the consequences from neglecting fractionality (and to propose a solution alleviating the bias), we choose an example from empirical capital structure research. Debt ratios of Compustat firms, for example, are clearly fractional, with almost $11 \%$ of all firm-year observations at the lower boundary value (i.e., having 0 leverage). Although there are only a few debt ratio observations at the upper boundary, it is important to be aware that we will never observe debt ratios below 0 or above $100 \%$.

A current issue in empirical capital structure research is to estimate the speed of adjustment (SOA) toward firms' target leverage. Accordingly, a large strand of the empirical literature focuses on estimating dynamic partial adjustment models in which the bounded debt ratio is the dependent variable. These models allow for imperfect and potentially infrequent adjustment over time (e.g., Leary and Roberts (2005), Flannery and Rangan (2006)). ${ }^{2}$ Very low empirical estimates of the SOA would contradict the relevance of the trade-off theory, favoring alternative explanations, which do not predict adjustment behavior toward target leverage after shocks, such as the pecking order theory or market timing.

The empirical evidence on adjustment speeds, in spite of using similar Compustat samples, is mixed and subject to an ongoing debate (Frank and Goyal (2008), Graham and Leary (2011)), as these studies use different adjustment speed estimators. Nickell (1981) shows that standard methods such as OLS or fixed effects may lead to seriously biased coefficient estimates in dynamic panel models. This has entered the recent capital structure literature as well. Flannery and Rangan (2006) and Huang and Ritter (2009) discuss estimators' properties for SOA estimation, also suggesting potentially less biased alternatives such as an instrumental-variables fixed effects estimator or the long difference estimator of Hahn, Hausman, and Kuersteiner (2007). Recently, Oztekin and Flannery (2012) and Flannery and Hankins (2013) have proposed the bias-corrected least-squares dummy variable (LSDVC) estimator of Kiviet (1995) and Bruno (2005a) as well as the Blundell-Bond (1998) estimator. These estimators have been found to have favorable properties for estimating partial adjustment models, as they are specifically designed to be consistent with dynamic panel data. ${ }^{3}$ Nevertheless, all these methods do not account for a fractional dependent

link to the relevant econometrics literature, we henceforth refer to this characteristic of the dependent variable as being fractional.

${ }^{2}$ The dynamic trade-off theory (Fischer, Heinkel, and Zechner (1989)) implies that nontrivial adjustment costs will lead to imperfect, and potentially infrequent, adjustment patterns. Leary and Roberts (2005) provide evidence that, on average, U.S. firms issue external financing only in 1 quarter of a fiscal year (i.e., they remain idle in 3 out of 4 quarters). Since most studies on capital structure determinants rely on yearly data, such a pattern will be correctly taken into account by a partial adjustment model.

${ }^{3}$ A panel data set includes cross-sectional observations for more than one time period. For example, data for $N$ firms over $T$ periods would be a balanced panel. If not all firms are observed in every year, the panel is said to be unbalanced (see, e.g., Greene (2011), p. 384). 
variable, which is a violation of the assumptions made and may thus result in biased adjustment speed estimates. ${ }^{4}$

In this paper, we propose a new estimator that is able to yield unbiased adjustment speed estimates for the standard partial adjustment model in the presence of a fractional dependent variable. The estimator is unbiased and consistent in the context of unbalanced dynamic panel data with a fractional dependent variable (DPF estimator) and accounts for fixed effects (i.e., unobserved, timeinvariant firm heterogeneity). The DPF estimator is a doubly censored Tobit estimator (with censoring at 0 and 1$),{ }^{5}$ relying on a latent variable approach to account for the fractional nature of the dependent variable. The latent variable approach distinguishes between a latent (i.e., unobservable) and an observable (but censored) dependent variable, which helps to overcome the censoring problem. The DPF estimator is a maximum likelihood estimator that builds on the work of Loudermilk (2007) and changes her specification of the presumed fixed effects distribution, such that it allows for unbalanced panel data, which we encounter in almost every corporate finance study. The estimator is not restricted to capital structure issues but can be applied in other areas of corporate finance in which partial adjustment models are used (e.g., adjustment behavior toward targets).

We conduct several simulation and resampling experiments to examine the bias of recently suggested estimators for adjustment speed (including BlundellBond (1998), long difference, and LSDVC estimators), as they do not account for the fractional nature of debt ratios. We also use these simulations to examine the statistical properties of the DPF estimator, in particular to analyze the estimator's robustness against a potential misspecification of the (required) assumption regarding the fixed effects' distribution.

First, we run Monte Carlo simulations that are based on the data-generating process of the DPF estimator, calibrated to resemble observed Compustat data on firm capital structures. Constructing the data with different true adjustment speeds, we estimate the SOA and derive bias curves for a comprehensive set of estimators. We find that the DPF estimator is unbiased in these settings, as expected, while all other estimators show substantial bias across different true speeds of adjustment. Initially, we analyze bias curves for a comprehensive set of estimators (including OLS, fixed effects, and Fama-MacBeth (1973)) to illustrate the severity of the problem, but given the already established biases of these estimators in the dynamic context, in subsequent analyses we focus on the comparison between the DPF estimator and the more recently suggested alternatives (i.e., Blundell-Bond (1998), long difference, and LSDVC; henceforth, benchmark estimators).

Second, we generate capital structure data that exhibit 0 true adjustment speed by resampling, that is, by repeatedly drawing with replacement from observed

\footnotetext{
${ }^{4}$ Chang and Dasgupta (2009), Iliev and Welch (2010), and, Flannery and Hankins (2013) also raise the issue of SOA estimates potentially being biased due to the bounded nature of leverage ratios. None of these studies offers a generalized econometric solution that would enable researchers to estimate unbiased adjustment speeds, though.

${ }^{5}$ The boundary values can be set to any other closed interval depending on the economic definition of the dependent variable.
} 
data. Resampling in general maintains the properties of the empirical (but unknown) distribution of the data, which constitutes one of our measures to test the distributional assumptions underlying the DPF estimator. In analogy to Chang and Dasgupta (2009), we generate leverage data based on observed financial deficits from Compustat, and we close these deficits by randomly issuing debt or equity. We then test whether the competing estimators are able to identify the absence of adjustment behavior in the data. We find that benchmark estimators falsely indicate positive adjustment behavior by estimating SOAs ranging from $15 \%$ to $22 \%$, whereas the DPF estimator is able to detect "mechanical mean reversion" and yields 0 adjustment speed.

Third, in another resampling experiment, we use observed debt and equity changes from Compustat to generate debt ratios that exhibit different adjustment speeds. Due to resampling, the generated data nevertheless maintain essential features of the empirical leverage distribution (Iliev and Welch (2010)). Except for the DPF and the W estimator, ${ }^{6}$ all estimators are severely biased. Some even yield the same estimate for two different underlying true adjustment speeds in the data. For example, an estimator may indicate 5\% adjustment speed for both a generated data set with underlying $10 \%$ and another generated data set with underlying $-10 \%$ adjustment speed. In these resampling experiments, the DPF estimator always provides a unique (and least biased) estimate of the SOA.

Fourth, we report that easy work-arounds for fractionality, such as discarding 0 leverage observations, or other percentiles of the distribution (see, for example, Flannery and Rangan (2006)), do not alleviate the bias of benchmark estimators.

The DPF estimator is a maximum likelihood estimator and makes the assumption of normally distributed error terms and fixed effects in combination with a specific parametric form of the fixed effects' density. A final set of simulations addresses potential limitations of the DPF estimator due to its distributional assumptions, which is a limitation that the benchmark estimators (Blundell-Bond (1998), long difference, and LSDVC) do not have. Maximizing the likelihood function based on an incorrect error term distribution is called quasi-maximum likelihood estimation, which might be biased. In order to test for a potential bias of the DPF estimator, we conduct several robustness tests. Following Bollerslev and Wooldridge (1992) in testing for quasi-maximum likelihood properties, we conduct Monte Carlo simulations in which we generate data with symmetric $t$-distributed and asymmetric $\chi^{2}$-distributed error terms instead of assuming normality. We find only a very small bias for negative and 0 adjustment speeds for the DPF estimator for $t$-distributed error terms, and no bias for higher true speeds of adjustment. Similarly, under a nonnormal fixed effects distribution, we do not find any notable changes in the unbiasedness of the DPF estimator.

After the analysis of the DPF estimator's statistical properties, we apply the estimator to Compustat firms over the period 1965-2009. For these data, standard estimators yield SOA estimates in the range of $15 \%$ to $40 \%$, similar to the

\footnotetext{
${ }^{6}$ The W estimator has been suggested by Welch (2004) and is a modified partial adjustment model that uses a simple OLS regression of the market debt ratio on lagged market debt ratio and an implied debt ratio that accounts for debt ratio changes caused by stock return effects. It can be applied only in the capital structure context.
} 
heterogeneity of estimates reported in other studies (e.g., Huang and Ritter (2009), Tab. 8). Using the DPF estimator, we find an SOA estimate for market leverage (book leverage) in the middle of this range at 26\% (27\%), which corresponds to a half-life of leverage shocks of about 2.3 years. ${ }^{7}$ This result is consistent with the trade-off theory and economically in line with "active managerial interventions," although it suggests, consistent with survey evidence (Graham and Harvey (2001)), that many firms do not give a high priority to quickly moving to a target.

Our estimate of the SOA for the full Compustat sample yields conclusions similar those of some other studies (or estimators, e.g., Blundell-Bond (1998)). The difference in estimates between an unbiased (DPF) and a biased estimator (Blundell-Bond), however, is not always marginal in real-world applications. For example, the analysis of cross-sectional differences in SOA has become the focus of the most recent capital structure research (see, e.g., Lockhart (2010), Faulkender, Flannery, Hankins, and Smith (2012), Hovakimian and Li (2012), and Oztekin and Flannery (2012)) because it seems unlikely that all firms have the same adjustment costs (Graham and Leary (2011)). We show that the DPF estimator and the Blundell-Bond estimator can lead to very different conclusions regarding SOA for subsamples, even if both estimators yield similar estimates for the full sample. Examining firms in different Standard \& Poor's (S\&P) rating categories, for which differential adjustment costs can be expected, the Blundell-Bond estimator yields a relatively flat and fast adjustment pattern across the different rating categories. In contrast, the DPF estimator indicates a U-shaped SOA pattern at slower levels.

Overall, in our simulation and resampling experiments we find that the DPF estimator is close to an unbiased adjustment speed estimator in the presence of a fractional dependent variable, unobserved heterogeneity, and unbalanced panel data. Apart from the unbiasedness, the DPF estimator has two important features that are crucial in nearly all applied corporate finance research that is concerned with adjustment speed estimation. First, it is immune to falsely identifying mechanical mean reversion as real adjustment behavior. Second, unlike most previously applied nonfractional estimators, ${ }^{8}$ the DPF estimator always gives unique estimates of the SOA for different true underlying adjustment speeds and only this allows it to compare adjustment speeds of different subsamples.

The remainder of the paper is structured as follows: Section II provides an overview of current empirical evidence on tests of dynamic trade-off theories. Furthermore, methodological issues regarding the econometrics of partial adjustment models with a fractional dependent variable are discussed, and the DPF estimator is presented. Section III contains Monte Carlo simulation and resampling experiments examining the bias of nonfractional estimation methods, and also providing an analysis of the statistical properties of the DPF estimator. In Section IV, we apply the estimator to the typical corporate finance data used in previous studies. Section V concludes.

\footnotetext{
${ }^{7}$ An autoregressive model of order $1(\mathrm{AR}(1))$ process has an exponentially declining response function to shocks. Half-life is the time the process needs to close the gap between the actual debt ratio and the target by $50 \%$, after a one-unit shock to the error term. Thus, half-life is calculated as $\log (0.5) / \log (1-$ speed of adjustment $)$.

${ }^{8}$ The W estimator is the only exception (see Iliev and Welch (2010)).
} 


\section{Speed of Adjustment Estimation}

In this section, we start with introducing the dynamic partial adjustment model, which is the workhorse model used to estimate SOA toward target leverage. Given the widely varying empirical estimates of the SOA in previous research, we highlight the econometric challenges of estimating partial adjustment models and briefly explain why the commonly used estimators (e.g., OLS, fixed effects, and generalized method of moments (GMM)) are biased if the dependent variable is fractional.

We then introduce the DPF estimator as our proposed solution to the identified econometric challenges, as this estimator specifically takes into account a fractional dependent variable in adjustment speed estimation.

\section{A. Evidence}

In the dynamic version of classic trade-off theory, target leverage can be time varying. If there are (for any reason) deviations from the optimal capital structure, the theory states that there will be adjustment toward the "optimal" target, although adjustment costs might prevent full adjustment. Capital structure research, using dynamic partial adjustment models, then strives to estimate the SOA.

The target leverage of firm $i$ at time $t+1$ is determined by a vector of firm characteristics $\boldsymbol{X}_{i t}$ that are related to the trade-off between the costs and benefits of debt and equity in different capital structures. It is given by

$$
\mathrm{LEV}_{i, t+1}^{*}=\boldsymbol{X}_{i t} \gamma
$$

where $\gamma$ is a coefficient vector, and LEV denotes the market debt ratio. For firms having a leverage target, there must be at least some elements of $\gamma$ that are different from 0 .

The partial adjustment model has the form:

$$
\mathrm{LEV}_{i, t+1}-\mathrm{LEV}_{i t}=\lambda\left(\mathrm{LEV}_{i, t+1}^{*}-\mathrm{LEV}_{i t}\right)+\epsilon_{i, t+1}
$$

Plugging target leverage (1) into model (2), the rearranged partial adjustment model is

$$
\mathrm{LEV}_{i, t+1}=\lambda\left(\boldsymbol{X}_{i t} \gamma\right)+(1-\lambda) \mathrm{LEV}_{i t}+c_{i}+\epsilon_{i, t+1}
$$

where $\lambda$ is the adjustment speed coefficient, $c_{i}$ is a time-invariant unobserved variable (firm fixed effect), and $\epsilon_{i, t+1}$ is an error term. The SOA is assumed to be the same for all firms and captures the extent to which deviations from optimal leverage are eliminated in each period. If $\lambda=0$, the SOA is 0 , that is, there is no adjustment toward the target leverage. If $\lambda=1$, the adjustment is immediate.

In the previous literature, simple pooled OLS, Fama-MacBeth (1973), or the fixed effects estimator have been common choices to estimate speeds of adjustment. Nickell (1981) shows that standard fixed effects estimators may lead to seriously biased coefficient estimates in dynamic panel models. The more recent capital structure literature employs the Blundell-Bond (1998) GMM estimator, the long difference estimator of Hahn et al. (2007), or the bias-corrected 
least-squares dummy variable (LSDVC) estimator of Kiviet (1995) and Bruno (2005a) that all do not suffer from the Nickell (1981) bias.

Empirical studies find estimates of the annual SOA that vary widely (between $0 \%$ and $40 \%$ ) using market debt ratios. For example, Fama and French (2002) and Kayhan and Titman (2007) find very low adjustment speeds of $7 \%$ to $18 \%$; Lemmon, Roberts, and Zender (2008) and Huang and Ritter (2009) estimate about 25\%; while Flannery and Rangan (2006), Leary and Roberts (2005), and Alti (2006) find relatively fast adjustments of $35 \%$ to $40 \%$. Welch (2004) tests adjustment to leverage shocks from stock price changes and finds no adjustment at all. ${ }^{9}$ Since all these studies rely on rather similar Compustat firm samples, it appears likely that these differences in SOA findings are attributable to differences in the estimation method, as Huang and Ritter argue.

\section{B. Methodological Issues}

Estimating dynamic partial adjustment models is econometrically challenging, because i) financial data on companies typically are unbalanced panel data, ii) the empirical model needs to allow for adjustment over time (i.e., a lagged dependent variable needs to be included as a regressor), and iii) the dependent variable is fractional. Thus, differences in empirical results are likely due to one or more of these econometric issues, given the heterogeneity in estimator choices and the similarity of firm samples.

For example, the fixed effects estimator (FE) takes the panel nature of the data into account, but the existence of lagged dependent variables leads to a correlation between the error term and the explanatory variables (i.e., endogeneity), which renders FE biased for fixed $T$ (and OLS or Fama-MacBeth (1973) regressions as well; see Nickell (1981)). ${ }^{10}$ The bias-corrected LSDVC estimator of Kiviet (1995) uses fixed effects and applies a bias correction. Bruno (2005a) modifies the LSDVC estimator to allow for unbalanced panel data. The instrumentalvariables fixed effects estimator used by Flannery and Rangan (2006), the GMM system estimator proposed by Blundell and Bond (1998), or the long difference estimator of Hahn et al. (2007) are also consistent with a lagged dependent variable in the panel context. Yet, even these estimators are potentially biased, since they do not take the fractional nature of the dependent variable into account.

Most standard econometric models are inappropriate for estimation if observed debt ratios are limited to varying between 0 and 1. Methods that account for the special nature of fractional dependent variables are scarce, because in a generalized nonlinear panel context it is not possible to separate the unobserved fixed effects from the maximum likelihood estimates of the explanatory variables' coefficients (the so-called "incidental parameters problem"). Since no known transformation eliminates the unobserved heterogeneity, either a

\footnotetext{
${ }^{9}$ Some other studies, like Titman and Tsyplakov (2007) and Strebulaev (2007), use their theoretical dynamic trade-off models to generate simulated capital structure data. Partial adjustment regressions using these simulated data yield fairly low speeds of adjustment, at about $7 \%$.

${ }^{10}$ Flannery and Hankins (2013) provide a detailed discussion of the bias associated with standard estimators in the capital structure and dynamic panel context. Since this paper focuses on the additional bias due to the dependent variable being fractional, we just refer to these discussions for brevity.
} 
semiparametric approach needs to be used for estimation, or the distribution of the unobserved heterogeneity (the fixed effects) needs to be specified explicitly (see Baltagi (2005), Loudermilk (2007)).

Papke and Wooldridge (2008) use a semiparametric approach allowing for unobserved heterogeneity and endogenous regressors. But their analysis does not consider specifications that include a lagged dependent variable. Loudermilk (2007) develops a Tobit specification for fractional response variables allowing for censored observations at both 0 and 1 ("doubly censored Tobit"), with a lagged dependent variable and unobserved heterogeneity. However, the Loudermilk estimator requires balanced panel data, which renders it inapplicable to corporate finance data, where entry and exit to the sample is very frequent and related either to the firm's capital structure itself or its determinants.

\section{DPF Estimator}

The DPF estimator is a doubly censored Tobit specification that allows for corner observations at both 0 and 1 , with a lagged dependent variable and unobserved heterogeneity. We introduce the DPF estimator that builds on the model of Loudermilk (2007) and changes her specification of the presumed fixed effects distribution, such that it allows for unbalanced panel data with a lagged dependent variable - the typical data structure encountered in capital structure research. The DPF estimator is easily implemented in Stata; see Internet Appendix B (available at www.jfqa.org) for details.

To take the fractional nature of the dependent variable into account, the DPF estimator employs a latent variable specification. The latent (unobservable) variable, $y_{i t}^{\#}$, in the small $T$, large $N$ panel model is given by

$$
y_{i t}^{\#}=Z_{i t} \varphi+\rho y_{i, t-1}+c_{i}+u_{i t},
$$

where $Z_{i t}$ is a set of exogenous regressors and $u_{i t} \sim N\left(0, \sigma_{u}^{2}\right)$ an error term. The observable doubly censored dependent variable $y_{i t}$ with two possible corner outcomes is given by

$$
y_{i t}= \begin{cases}0 & \text { if } \quad y_{i t}^{\#} \leq 0, \\ y_{i t}^{\#} & \text { if } 0<y_{i t}^{\#}<1 \\ 1 & \text { if } \quad y_{i t}^{\#} \geq 1\end{cases}
$$

In economic terms, a latent variable reflecting a firm's debt ratio can be interpreted as the firm's debt capacity. This capacity can exceed $100 \%$ of current total assets, for example, if the firm is so profitable that expected distress costs are negligible and the tax shield effect of interest payments on debt would be fully exploited only with a much larger debt level. The corresponding observable debt ratio takes the value 1 . Similarly, a negative debt capacity can arise if a firm is subject to high agency costs and opacity, such as may apply to start-up companies investing in research and development (R\&D) for new technologies. The firm's observable debt ratio takes the value 0 .

The model requires the specification of a conditional distribution for unobserved heterogeneity $c_{i}$ (i.e., the fixed effects), and variables other than the lagged 
dependent variable must be strictly exogenous. Under these model assumptions the explanatory variables and the error term will be independent, conditionally on the fixed effects. Thus, consistency is achieved by including the fixed effects as regressors.

The time-invariant unobserved variable is

$$
c_{i}=\alpha_{0}+\alpha_{1} y_{i 0}+\overline{\boldsymbol{Z}}_{i} \boldsymbol{\alpha}_{2}+a_{i}
$$

with error term $a_{i} \sim N\left(0, \sigma_{a}^{2}\right)$ and $\overline{\boldsymbol{Z}}_{i}$ being the time-series averages of $\boldsymbol{Z}_{\boldsymbol{i t}}$. This choice of distribution for the fixed effect $c_{i}$ allows a correlation structure between the regressors of the model and the fixed effect. The term $\alpha_{1} y_{i 0}$ deals with the initial condition problem in dynamic nonlinear panel data, as suggested by Wooldridge (2005). Loudermilk (2007) includes all observations of $\boldsymbol{Z}_{i t}$ in her fixed effects specification and thus requires the fixed effects to depend on a balanced panel. In contrast to Loudermilk, we assume that the fixed effects distribution depends on time-series averages of the exogenous variables, which are robust to (randomly) missing values in the $\boldsymbol{Z}$ matrix (see, for instance, Mundlak (1978), Chamberlain (1980)). The derivation of the theoretical building blocks of the model and its maximum likelihood estimation can be found in Internet Appendix A.

\section{Simulation and Resampling Experiments}

In the previous section, we introduced the DPF estimator as our solution to the identified econometric challenges in adjustment speed estimation in corporate finance: a fractional and lagged dependent variable, unobserved heterogeneity, and unbalanced panel data.

We show in this section that methods typically applied in the previous literature yield severely biased estimates of the SOA in some situations, thus leading to potentially flawed economic conclusions. To illustrate the resulting biases for different true adjustment speeds, and to test the properties and robustness of the DPF estimator, we conduct several simulation and resampling experiments. First, we run Monte Carlo simulations that are based on the data-generating process of the DPF estimator. The resulting bias curves and their implications hold generally for the estimation of partial adjustment models with a fractional dependent variable (e.g., also when analyzing share repurchase or cash holding ratios), although we have calibrated the data to resemble leverage patterns of Compustat firms.

Second, by resampling observed financial deficits from Compustat and simulating random financing, we test whether the competing estimators are subject to the problem of "mechanical mean reversion" (Chang and Dasgupta (2009)), that is, systematically indicating active adjustment if actually there is none.

Third, in another resampling experiment, we use observed debt and equity changes from Compustat to generate debt ratio dynamics that exhibit different true adjustment speeds but maintain the empirical distribution of observed firm leverage due to the resampling. We use this experiment to address the issue raised by Iliev and Welch (2010) that standard estimators have nonmonotonic bias curves, that is, the same estimated adjustment speed results for different underlying true speeds of adjustment. 
In addition, we examine easy work-arounds to the problem of a fractional dependent variable suggested in the literature, such as dropping all 0 corner observations or, in the leverage context, using different measures of leverage. These work-arounds do not change the bias of the benchmark estimators, though.

Finally, we address two potential concerns regarding the DPF estimator. We examine the robustness of the DPF estimator if we misspecify the set of variables that measures target leverage in the regression design, or if the data violate the DPF's distributional assumptions of normality of the error terms and fixed effects.

\section{A. Monte Carlo Simulations}

\section{Data-Generating Process}

In setting up the Monte Carlo simulations, we choose a single exogenous regressor ${ }^{11}$ representing the firm characteristics that determine target leverage, and set $Z_{i, t} \varphi$ in equation (4) to $\lambda X_{i t} \gamma$, which is target leverage $\mathrm{LEV}_{i, t+1}^{*}$ multiplied by the SOA $\lambda$ in the partial adjustment model in equation (3). Equivalently, we set $\rho y_{i, t-1}$ to $(1-\lambda) \mathrm{LEV}_{i, t}$ in order to obtain the dynamics of the latent variable

$$
\mathrm{LEV}_{i, t+1}^{\#}=\lambda\left(X_{i t} \gamma\right)+(1-\lambda) \mathrm{LEV}_{i t}+c_{i}+u_{i, t+1}
$$

The parameter choices in the simulations are as follows: The single (exogenous) fixed regressor is uniformly distributed $X_{i t} \sim U(-0.5,1)$ with $\gamma=1 .^{12}$ The timeinvariant unobserved variable is

$$
c_{i}=\alpha_{0}+\alpha_{1} \operatorname{LEV}_{i 0}+\frac{1}{T} \sum_{t=0}^{T} X_{i t} \alpha_{2}+a_{i},
$$

with $a_{i} \sim N\left(0, \sigma_{a}^{2}\right)$, where $\sigma_{a}=0.1, \alpha_{0}=0.1, \alpha_{1}=0.1$, and $\alpha_{2}=-0.25$. The initial latent variable is given by

$$
\mathrm{LEV}_{i 0}^{\#}=\lambda\left(X_{i 0} \gamma\right)+\alpha_{0}+\frac{1}{T} \sum_{t=0}^{T} X_{i t} \alpha_{2}+a_{i}+u_{i 0}
$$

and $u_{i 0} \sim N\left(0, \sigma_{u}^{2}\right)$ with $\sigma_{u}=0.1$.

\section{Simulated Data Characteristics}

It should not be surprising if the DPF estimator performed well (with respect to unbiasedness and efficiency) under our specification of the simulated data, simply because as a maximum likelihood estimator it is designed to do so in this situation. However, since the simulated data closely resemble actual data on debt ratios for some parameter choices, we can learn about the biases of other

\footnotetext{
${ }^{11}$ Flannery and Hankins (2013) use several exogenous variables in their simulations. We also run our simulations using more than one exogenous regressor with and without a correlation structure between these regressors and do not find any significant differences in the estimates of the adjustment speed.

${ }^{12}$ Note that the implied target $\mathrm{LEV}_{i, t+1}^{*}=X_{i t} \gamma$ may be smaller than 0 or larger than 1.
} 
estimators that are commonly applied in the literature. ${ }^{13}$ We consider the consequences of misspecification of the data-generating process for the statistical properties of the DPF estimator in Section III.C.

When comparing simulated data to actual data on leverage, it is important to stress that we do not know the true distribution of the underlying actual debt ratios. We do not know the best-fitting parameters a priori, and in fact, we wish to compare the characteristics of different estimators over a wide range of values for the SOA parameter $\lambda$. This parameter essentially determines the frequency of corner observations, which in turn has a major impact on the mean of the leverage distribution. However, one should expect the shape of the distribution to resemble the shape of the true distribution. In particular, this implies that we must compare the simulated and true data with regard to the overall shape, standard deviation of the debt ratios, and number of 0 observations, because the latter is the main issue of censored actual data.

Figure 1 contains a histogram of the relative frequency distribution of market debt ratios for the Compustat firm universe (Graph A). The histogram in Graph B is the debt ratio distribution of one simulated data set based on the general datagenerating process from Section III.A.1, assuming an SOA of $\lambda=0.3$. As can be seen, the simulated data mimics the actual data in terms of the large peak at the lower censoring point of 0 (i.e., no indebtedness), and the decay of leverage toward larger values. The distribution differs regarding the upper censoring limit of 1 , where the simulated data have significantly more extreme observations at the border point ( $2.75 \%$ vs. $0.02 \%$; see Table 1$)$. However, this depends strongly on the choice of adjustment speed. The relative frequency distribution of predicted market debt ratios, based on DPF estimation, is depicted in Graph C of Figure 1. The estimated SOA for actual data is about $26 \%$ (see Section IV.B).

Table 1 presents sample statistics for the simulated data under different values for the SOA parameter $\lambda$. Comparing this with the descriptive statistics

\section{FIGURE 1}

Histograms for the Frequency Distributions of Actual, Simulated, and Predicted Market Debt Ratios

Graph A in Figure 1 shows the relative frequency distribution of the actual data market debt ratios in the Compustat sample for the period 1965-2009. Graph B shows the relative frequency distribution of simulated market debt ratios, using the data-generating process from Section III.A. 1 with an SOA $\lambda=0.3$, that is $30 \%$, from one Monte Carlo simulation. The relative frequency distribution of the predicted market debt ratios, based on the DPF estimation for the Compustat sample, is depicted in Graph C in this figure.
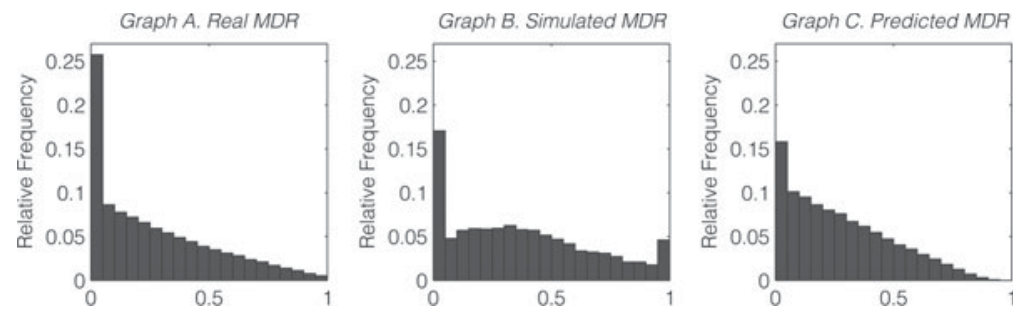

${ }^{13}$ Other papers in the literature also use simulated data to analyze capital structure theories based on the data-generating process of an estimator (e.g., Huang and Ritter (2009), Flannery and Hankins (2013), and Iliev and Welch (2010)) or on structural models (e.g., Strebulaev (2007), Fischer et al. (1989)). 
TABLE 1

Average Sample Statistics for Simulated Data

\begin{tabular}{|c|c|c|c|c|c|c|}
\hline True $\lambda$ & -0.2 & 0.0 & 0.2 & 0.3 & 0.5 & 0.8 \\
\hline Mean $\left(\mathrm{LEV}_{i t}\right)$ & $\begin{array}{c}0.309 \\
(0.182)\end{array}$ & $\begin{array}{c}0.324 \\
(0.168)\end{array}$ & $\begin{array}{c}0.347 \\
(0.164)\end{array}$ & $\begin{array}{c}0.351 \\
(0.172)\end{array}$ & $\begin{array}{c}0.354 \\
(0.212)\end{array}$ & $\begin{array}{c}0.366 \\
(0.293)\end{array}$ \\
\hline $\operatorname{Mean}\left(X_{i t}\right)$ & $\begin{array}{c}0.250 \\
(0.426)\end{array}$ & $\begin{array}{c}0.250 \\
(0.426)\end{array}$ & $\begin{array}{c}0.250 \\
(0.426)\end{array}$ & $\begin{array}{c}0.250 \\
(0.426)\end{array}$ & $\begin{array}{c}0.250 \\
(0.426)\end{array}$ & $\begin{array}{c}0.250 \\
(0.426)\end{array}$ \\
\hline $\operatorname{Mean}\left(c_{i}\right)$ & $\begin{array}{c}0.044 \\
(0.112)\end{array}$ & $\begin{array}{c}0.046 \\
(0.113)\end{array}$ & $\begin{array}{c}0.050 \\
(0.114)\end{array}$ & $\begin{array}{c}0.052 \\
(0.114)\end{array}$ & $\begin{array}{c}0.058 \\
(0.115)\end{array}$ & $\begin{array}{c}0.068 \\
(0.117)\end{array}$ \\
\hline $\begin{array}{l}\operatorname{Mean}\left(\operatorname{Corr}\left(c_{i}, X_{i t}\right)\right) \\
\operatorname{Corr}\left(c_{i}, \operatorname{LEV}_{i 0}\right) \\
\operatorname{Obs}\left(\operatorname{LEV}_{i t}=0\right) \\
\operatorname{Obs}\left(\operatorname{LEV}_{i t}=1\right)\end{array}$ & $\begin{array}{r}-0.116 \\
0.615 \\
0.360 \\
0.156\end{array}$ & $\begin{array}{r}-0.110 \\
0.632 \\
0.264 \\
0.113\end{array}$ & $\begin{array}{r}-0.097 \\
0.555 \\
0.162 \\
0.048\end{array}$ & $\begin{array}{r}-0.094 \\
0.511 \\
0.140 \\
0.028\end{array}$ & $\begin{array}{r}-0.088 \\
0.436 \\
0.145 \\
0.017\end{array}$ & $\begin{array}{r}-0.072 \\
0.353 \\
0.220 \\
0.029\end{array}$ \\
\hline
\end{tabular}

provided in Section IV.A further illustrates the similarity between the simulated and the observed data, but also shows that the simulated data do not fit perfectly. For example, for $\lambda=0.3$, the standard deviation of the simulated debt ratios is $17 \%$, compared to an empirical estimate of $25 \%$, and the number of 0 -observations is $14 \%$ as opposed to $11 \%$.

\section{Comparison of Estimation Results}

We compare adjustment speed estimates, using the simulated capital structure data, of methods used in the previous literature. The list of estimators includes pooled OLS, Fama-MacBeth (1973), the fixed effects estimator, the BlundellBond (1998) estimator, the long difference estimator, and the LSDVC estimator. ${ }^{14}$ Finally, adjustment speeds are compared with the DPF estimator.

Figure 2 and Table 2 present the simulation results. In Graph A, the figure shows the average SOA estimates across 500 Monte Carlo runs for each value of the true SOA. The horizontal axis shows the true parameter underlying the simulation and the vertical axis the corresponding average of the estimated coefficients. The generated latent debt ratios $\mathrm{LEV}_{i, t+1}^{\#}$ are censored at 0 and 1 to yield the observable $\mathrm{LEV}_{i, t+1}$, and the number of cross sections and time periods are set to $N=1,000$ and $T=8$, respectively.

Given the results of Nickell (1981) and Huang and Ritter (2009), it is not surprising that pooled OLS ("OLS"), the Fama-MacBeth (1973) estimator ("FamaMac"), and the fixed effects estimator ("FixEff") show large bias. The OLS and Fama-MacBeth estimators severely underestimate the true SOA, while using fixed effects leads to an overestimation.

Out of the recently suggested benchmark estimators in the previous capital structure literature, when there is censoring the long difference estimator ("LD")

\footnotetext{
${ }^{14}$ Throughout the paper, we follow Flannery and Hankins (2013) in using the 2-step Blundell-Bond (1998) estimator and the LSDVC estimator using Arellano and Bond (1991) estimates to initialize the bias correction. For the long difference estimator we use a 7-year differencing window.
} 
FIGURE 2

\section{Bias Curves for Simulated Data}

Figure 2 shows the average estimates of the SOA $\lambda$ from 500 replications for each value of $\lambda$, using panel data with $N=1,000$ cross sections and $T=8$ periods throughout. The data-generating process is

$$
\operatorname{LEV}_{i, t+1}^{\#}=\lambda\left(X_{i t} \gamma\right)+(1-\lambda) \operatorname{LEV}_{i t}+c_{i}+u_{i, t+1}
$$

where $\mathrm{LEV}_{i, t+1}^{\#}$ is the latent debt ratio. In Graph $\mathrm{A}$, the latent debt ratio $\mathrm{LEV}_{i, t+1}^{\#}$ is censored according to

$$
\mathrm{LEV}_{i t}= \begin{cases}0 & \text { if } \operatorname{LEV}_{i t}^{\#} \leq 0, \\ \operatorname{LEV}_{i t}^{\#} & \text { if } 0<\operatorname{LEV}_{i t}^{\#}<1, \\ 1 & \text { if } \operatorname{LEV}_{i t}^{\#} \geq 1,\end{cases}
$$

where $\mathrm{LEV}_{i t}$ is the observable debt ratio that is restricted to the unit interval. In Graph $\mathrm{B}$, the latent debt ratio LEV $\#$ i,t+1 is not censored, that is, the observable debt ratio equals the latent debt ratio $\mathrm{LEV}_{i t}=\mathrm{LEV}_{i, t+1}^{\#}$ and can assume values outside the unit interval. The details of the data-generating process are described in Section III.A.1. In each graph, the horizontal axis shows the true parameter choice for $\lambda$ in the simulation, and the vertical axis, the corresponding estimated coefficient. The results are reported for different estimators: pooled OLS ("OLS"), Fama-MacBeth ("FamaMac") (1973), fixed effects ("FixEff"), Blundell-Bond ("BlunBo") (1998), long difference ("LD"), LSDVC ("LSDVC"), and DPF estimator ("DPF").
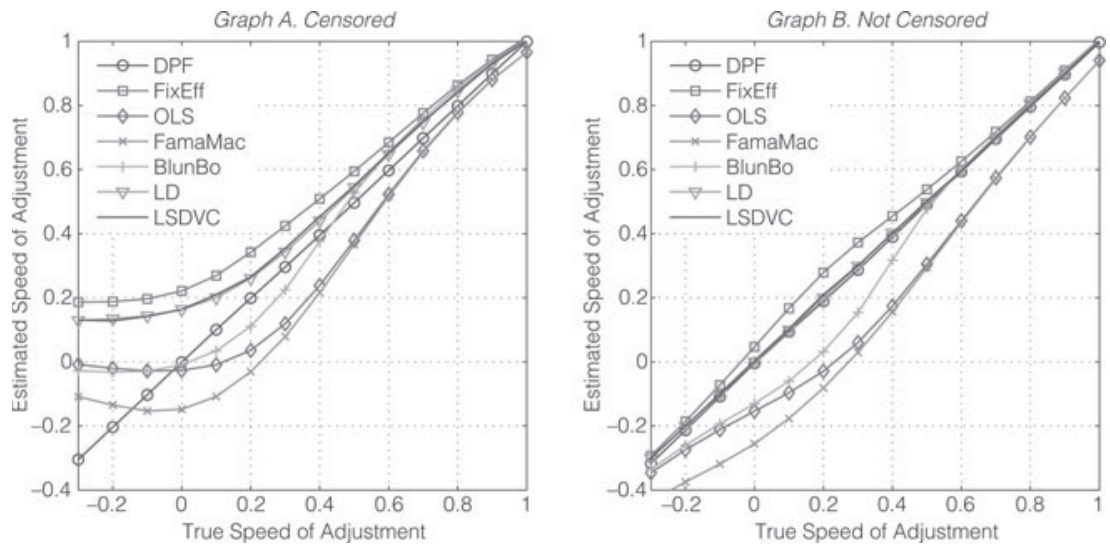

overestimates the SOA, with increasing bias for lower true speeds of adjustment $\lambda$. The LSDVC estimator ("LSDVC") almost coincides with the long difference estimator bias curve. The Blundell-Bond (1998) estimator underestimates for low adjustment speeds and overestimates for higher adjustment speeds.

Finally, the straight line between the other parameters represents the average estimate of the DPF estimator. ${ }^{15}$ This number coincides almost perfectly with the true value (with a deviation of less than $0.4 \%$; see Table 2), demonstrating that the DPF estimator is unbiased, as it should be, given that the data are constructed using its data-generating process.

For true negative adjustment speeds (if the dependent variable is moving systematically away from its target), estimated adjustment speeds are nondecreasing (and mostly nonnegative) for slower true adjustment speeds. Particularly troublesome is the result for the Fama-MacBeth (1973) estimator, where the estimated

\footnotetext{
${ }^{15}$ The Tobit model allows inference with respect to the latent uncensored variable and the observable censored variable. We focus on the true SOA in the following (i.e., analyzing the latent variable). Marginal effects then are linear and correspond to the estimated coefficient (see Greene (2011), p. 889).
} 
TABLE 2

Average Bias of Estimators for Simulated Data

Table 2 presents each estimator's average bias (estimated value - true value) for different adjustment speeds $\lambda$, based on Monte Carlo simulations with data designed to resemble typical Compustat data on leverage. Average estimates of the SOA $\lambda$ are from 500 replications for each value of $\lambda$, using panel data with $N=1,000$ cross sections and $T=8$ periods throughout. These results are also illustrated by Figure 2. Panel A contains the bias for the simulations with censored latent market debt ratios LEV $\#$, and Panel $\mathrm{B}$, the bias for simulations with uncensored latent market debt ratios LEV \# apply the 2-step Blundell-Bond (1998) estimation; the LSDVC estimator's bias correction is initialized with the ArellanoBond (1991) estimates; the long difference estimator is applied with a 7-year differencing window.

\begin{tabular}{|c|c|c|c|c|c|c|}
\hline True $\lambda$ & -0.2 & 0.0 & 0.2 & 0.3 & 0.5 & 0.8 \\
\hline \multicolumn{7}{|c|}{ Panel A. Censoring } \\
\hline $\begin{array}{l}\text { DPF } \\
\text { Fixed effects } \\
\text { OLS } \\
\text { Fama-MacBeth } \\
\text { Blundell-Bond } \\
\text { Long difference } \\
\text { LSDVC }\end{array}$ & $\begin{array}{r}-0.003 \\
0.388 \\
0.180 \\
0.065 \\
0.168 \\
0.335 \\
0.324\end{array}$ & $\begin{array}{r}-0.001 \\
0.221 \\
-0.027 \\
-0.148 \\
-0.009 \\
0.163 \\
0.166\end{array}$ & $\begin{array}{r}-0.002 \\
0.142 \\
-0.164 \\
-0.231 \\
-0.089 \\
0.061 \\
0.070\end{array}$ & $\begin{array}{r}-0.004 \\
0.125 \\
-0.181 \\
-0.221 \\
-0.075 \\
0.044 \\
0.052\end{array}$ & $\begin{array}{r}-0.004 \\
0.094 \\
-0.121 \\
-0.133 \\
0.028 \\
0.044 \\
0.050\end{array}$ & $\begin{array}{r}-0.002 \\
0.063 \\
-0.022 \\
-0.024 \\
0.053 \\
0.045 \\
0.046\end{array}$ \\
\hline \multicolumn{7}{|c|}{ Panel B. No Censoring } \\
\hline $\begin{array}{l}\text { DPF } \\
\text { Fixed effects } \\
\text { OLS } \\
\text { Fama-MacBeth } \\
\text { Blundell-Bond } \\
\text { Long difference } \\
\text { LSDVC }\end{array}$ & $\begin{array}{r}-0.013 \\
0.014 \\
-0.074 \\
-0.174 \\
-0.060 \\
0.000 \\
0.001\end{array}$ & $\begin{array}{r}-0.004 \\
0.047 \\
-0.154 \\
-0.256 \\
-0.130 \\
0.000 \\
0.003\end{array}$ & $\begin{array}{r}-0.011 \\
0.079 \\
-0.229 \\
-0.281 \\
-0.168 \\
-0.000 \\
0.003\end{array}$ & $\begin{array}{r}-0.013 \\
0.072 \\
-0.240 \\
-0.270 \\
-0.146 \\
-0.001 \\
0.002\end{array}$ & $\begin{array}{r}-0.008 \\
0.038 \\
-0.195 \\
-0.206 \\
-0.023 \\
-0.003 \\
0.000\end{array}$ & $\begin{array}{r}-0.004 \\
0.013 \\
-0.099 \\
-0.099 \\
0.006 \\
0.004 \\
0.002\end{array}$ \\
\hline
\end{tabular}

curve increases slightly for lower speeds of adjustment, such that the true adjustment speeds of 0.1 and -0.3 yield the same estimate of $-0.1 .^{16}$

Note that even if negative speeds of adjustment appear counterintuitive at first glance (and thus irrelevant), this is in particular not true in the capital structure context, because explanations competing with the trade-off theory can predict such an adjustment pattern. For example, as suggested by Baker and Wurgler (2002) and Dittmar and Thakor (2007), market timing of firms can lead to a systematically negative SOA. To illustrate, consider market timing that arises because of sustained stock price run-ups due to mispricings. The price run-up increases the market value of firms' equity and induces equity issues. Both effects (i.e., the stock price run-up and equity issuances) will lower market leverage and move firms further away from some target debt ratio (all else being equal). Thus, the nonuniqueness of SOA estimates for some estimators does not only prevent bias-correction schemes, but it also biases the evidence against alternative capital structure explanations.

In order to examine the impact of the fractional nature of the dependent variable on these biases, we repeat the simulation analysis, but apply the estimators to the latent variable, $\mathrm{LEV}_{i t}^{\#}$. Thus, the dependent variable is not fractional, such that Graph B in Figure 2 illustrates the bias resulting from analyzing a standard dynamic panel data set with a lagged dependent variable. Allowing the dependent variable to take on values lower than 0 and larger than 1 changes the estimation results significantly. Nevertheless, the OLS and Fama-MacBeth (1973) estimators are still heavily biased. The fixed effects estimator still exhibits a systematic bias (Nickell (1981)) over a large range of true $\lambda$, but the bias is significantly reduced.

\footnotetext{
${ }^{16}$ Iliev and Welch (2010) report similar results.
} 
The benchmark estimators are designed for this type of data, and LSDVC as well as the long difference estimator are indeed unbiased (Panel B of Table 2). The Blundell-Bond (1998) estimator still shows substantial bias for low true adjustment speeds. ${ }^{17}$ The best performing estimator remains the DPF estimator.

\section{B. Resampling Actual Data}

\section{Random Financing and Mechanical Mean Reversion}

Resampling maintains the properties of the empirical (but unknown) distribution of the data, if carefully designed. With resampling we are able to examine the statistical properties of estimators using actually observed data, as opposed to using simulated data with known properties of the underlying data-generating process. Since the DPF estimator relies on specific distributional assumptions and a parametric specification of the fixed effects' density, using resampled data also provides one of our tests for the robustness of the estimator with respect to these assumptions (also see Section III.C.3).

Chang and Dasgupta (2009) suggest a resampling approach in which they generate debt ratio dynamics evolving from randomly issuing or repurchasing debt or equity to close observed financial deficits, which represents an interesting benchmark case without target adjustment. In their analysis the standard fixed effects estimator yields a positive SOA, even though changes in leverage occur purely at random. Their explanation is that the fact that debt ratios remain in the $[0,1]$ interval is attributed by standard estimators to mean reversion (so-called "mechanical" mean reversion). In this section, we test whether the DPF and the benchmark estimators are able to detect 0 adjustment if there is none in the data due to random financing.

In the model, the financial deficit is $y_{t}$. With probability $p$, the firm issues debt and with probability $1-p$, it issues equity to finance the deficit. Thus, debt ratio dynamics are

$$
\mathrm{LEV}_{t+1}-\mathrm{LEV}_{t}= \begin{cases}\frac{D_{t}+y_{t}}{D_{t}+E_{t}+y_{t}}-\frac{D_{t}}{D_{t}+E_{t}} & \text { with probability } \quad p, \\ \frac{D_{t}}{D_{t}+E_{t}+y_{t}}-\frac{D_{t}}{D_{t}+E_{t}} & \text { with probability } 1-p\end{cases}
$$

In our simulations, we use equation (5) and calculate the financial deficit for each firm in our Compustat sample as

$$
\begin{aligned}
y_{t} & =\mathrm{NDI}_{t, t+1}+\mathrm{NEI}_{t, t+1}, \\
& =\left(D_{t+1}-D_{t}\right)+\left(E_{t+1}-E_{t}\left(1+r_{t, t+1}\right)\right),
\end{aligned}
$$

where NDI is the net book debt issue and NEI the net market equity issue controlled for stock returns without dividends $r .{ }^{18}$ The median relative financing deficit is about $5 \%$ of the sum of market equity and book debt. In roughly $56 \%$ of the firm-years, firms have positive financing deficits.

\footnotetext{
${ }^{17}$ This bias seems to be due to the inclusion of $\lambda$ in the coefficient on the independent variable, as implied by the partial adjustment model, which is the only difference to the data-generating process of the Blundell-Bond (1998) estimator.

${ }^{18}$ Details on the actual data sample can be found in Section IV.A.
} 
In Table 3, column 1 contains the regression results for generated debt ratios, according to the model in equation (5). Each firm starts with its actual initial market debt ratio. If the actual financing deficit in a firm-year is positive, the firm issues debt or equity with probability $p=0.5$. Similarly, if the financing deficit is negative, the firm randomly retires debt or equity. The LSDVC estimator in our regressions yields an average coefficient estimate on the lagged dependent variable of 0.78 , that is, an adjustment speed of $22 \%$. The Blundell-Bond (1998) and long difference estimators yield an adjustment speed of about $15 \% .{ }^{19}$ Unlike the benchmark estimators, the DPF estimator indicates a 0 adjustment speed, with a coefficient estimate of 1.013 for $1-\lambda$. Column 2 contains the regression results, when the financing deficit for each firm-year is resampled from the distribution of the actual deficits. The results are very similar to the estimates if every firm is assigned its actual deficit.

\section{TABLE 3}

Speed of Adjustment and Random Financing

Table 3 presents estimation results for the coefficient on lagged leverage $(=1-\mathrm{SOA})$ for resampled data of firms' financial deficits with random financing, similar to the design suggested by Chang and Dasgupta (2009). Column 1 (Actual Deficit) contains the average simulation results of estimating the partial adjustment model $\mathrm{LEV}_{t+1}=\lambda \mathrm{LEV}_{t+1}^{*}+(1-\lambda) \mathrm{LEV}_{t}$ without knowledge of the target, using the regression specification

$$
\operatorname{LEV}_{i, t+1}=c+(1-\lambda) \operatorname{LEV}_{i t}+u_{i, t+1}
$$

for generated debt ratios according to the model in equation (5). Each firm starts with its actual initial market debt ratio. If the actual financing deficit in a firm-year is positive, the firm issues debt or equity with probability $p=0.5$, that is by using "random financing." Similarly, if the financing deficit is negative, the firm randomly retires debt or equity. Column 2 (Random Deficit) contains the average estimates (standard deviations in parentheses), if the financing deficit for each firm-year is resampled from the distribution of the actual deficits. Mean( $\left.\mathrm{LEV}_{i t}\right)$ stands for the mean and $\mathrm{Std}\left(\mathrm{LEV}_{i t}\right)$ for the standard deviation of simulated market debt ratios. The relative number of 0 debt ratios is given in row "Obs $\left(\mathrm{LEV}{ }_{i t}=0\right)$ " and the number of debt ratios equal to 1 is given in row "Obs $\left(\mathrm{LEV}_{i t}=1\right)$." The number of replications is 500 for each specification

\begin{tabular}{|c|c|c|}
\hline & \multicolumn{2}{|c|}{$p=0.5$} \\
\hline & Actual Deficit & Random Deficit \\
\hline & 1 & 2 \\
\hline DPF & $\begin{array}{c}1.013 \\
(0.003)\end{array}$ & $\begin{array}{c}0.969 \\
(0.004)\end{array}$ \\
\hline Blundell-Bond & $\begin{array}{c}0.846 \\
(0.004)\end{array}$ & $\begin{array}{c}0.826 \\
(0.004)\end{array}$ \\
\hline Long difference & $\begin{array}{c}0.841 \\
(0.004)\end{array}$ & $\begin{array}{c}0.827 \\
(0.004)\end{array}$ \\
\hline LSDVC & $\begin{array}{c}0.784 \\
(0.003)\end{array}$ & $\begin{array}{c}0.818 \\
(0.003)\end{array}$ \\
\hline $\begin{array}{l}\operatorname{Mean}\left(\operatorname{LEV}_{i t}\right) \\
\operatorname{Std}\left(\operatorname{LEV}_{i t}\right) \\
\left.\operatorname{Obs}_{\left(\operatorname{LEV}_{i t}\right.}=0\right) \\
\operatorname{Obs}\left(\operatorname{LEV}_{i t}=1\right)\end{array}$ & $\begin{array}{l}0.367 \\
0.345 \\
0.206 \\
0.092\end{array}$ & $\begin{array}{l}0.374 \\
0.334 \\
0.194 \\
0.078\end{array}$ \\
\hline
\end{tabular}

In summary, the main implication from this analysis of resampled financing deficits is that the DPF estimator is able to identify 0 adjustment speed, while

\footnotetext{
${ }^{19}$ Using actual financing deficits in the simulations leads to generated debt ratios outside the unit interval. We censor debt ratios that are smaller than 0 or larger than 1 immediately in each period. We also check the robustness of our results in random subsamples of firms and across different periods of the full sample and find that all estimates are quite robust. Moreover, we check for the impact of a different censoring mechanism; that is, we first generate the complete panel data and introduce censoring only afterward. The results for the DPF estimator always indicate a 0 or moderate negative adjustment speed. If we do not censor at all, for example, OLS and Fama-MacBeth (1973) yield negative SOA estimates and the DPF yields highly negative SOA estimates.
} 
the benchmark estimators are not. The SOA describes whether conditional on a deviation from the target there is a systematic change in leverage to counteract the deviation. In the random financing case, there is no counteracting effect because the choice between debt/equity is independent from the past deviation from the target. Leverage does not systematically move toward the target, that is, there is no mechanism thats moves leverage up if the deviation (defined as actual minus target leverage) is negative, and down if the deviation is positive. Rather, it is equally likely that leverage will move away from or toward the target due to the random choice between equity and debt issuance. Hence, SOA as a measure of linear dependence between target deviation and leverage change will be equal to 0 . The benchmark estimators fail to identify this independence because the observable leverage process is censored. In contrast, since the DPF estimator considers explicitly the latent (and thus uncensored) dependent variable, it is able to identify independence between deviation and leverage changes, thus estimating an SOA of 0.

\section{Data-Generating Process Based on Observed Debt and Equity Changes}

Iliev and Welch (2010) suggest examining properties of SOA estimators by relying on the (unknown) true leverage distribution through resampling the observed data. Their basic idea is to separate stock price-induced changes in the market value of equity from those leverage changes that are due to capital measures initiated by firm management.

The dynamics of the true $\mathrm{LEV}_{i, t+1}$ process in a partial adjustment model, ${ }^{20}$

$$
\mathrm{LEV}_{i, t+1}=\lambda \mathrm{LEV}_{i, t+1}^{*}+(1-\lambda) \mathrm{LEV}_{i t}+\left[\epsilon_{i, t+1}\right]
$$

assuming no target leverage $(\lambda=0)$, can be rewritten as a function of changes in its components' debt and equity,

$$
\mathrm{LEV}_{i, t+1}=\frac{\mathrm{LEV}_{i t}}{\mathrm{LEV}_{i t}+\frac{\left(\mathrm{STK} \_\mathrm{RET}\right)\left(\widehat{\mathrm{EQ} \_I S S}\right)}{\text { DEBT_ISS }}\left(1-\mathrm{LEV}_{i t}\right)}
$$

In equation (6), STK_RET is the observed gross stock return without dividends for firm $i$ from period $t$ to $t+1$ (e.g., a 5\% capital gain is measured as 1.05). The observed stock returns are multiplied by EQ_ISS, which is the resampled gross relative net equity issuance (e.g., a 10\% net equity issuance is measured as 1.10). This product gives the total relative change in equity. The term DEBT_ISS is the resampled gross relative net debt issuance (e.g., a $-20 \%$ net debt issuance is measured as 0.80). The tilde indicates resampled variables, where net equity and debt issuances are resampled from randomly chosen sample firms (i.e., independent of firm $i$ itself). ${ }^{21}$

\footnotetext{
${ }^{20}$ Iliev and Welch (2010) do not add an error term to their leverage process. However, unexplained variability of debt ratios $\epsilon_{i, t+1}$ accounts for about $10 \%$ of the variability in debt ratios in the actual data. Thus, we add a normally distributed error term with 0 mean and $10 \%$ standard deviation in the simulations.

${ }^{21}$ Debt and equity changes are taken from the Compustat sample described in Section IV.A. For the simulation, certain assumptions have to be made for the cases where debt changes are not defined
} 
The resulting $\mathrm{LEV}_{i, t+1}$ process in equation (7) is the benchmark case for examining whether a given estimator is able to detect nonadjustment, if there is no adjustment under the data-generating process. Note that this is the most important case for capital structure research, since the trade-off theory would then be economically irrelevant.

To introduce adjustment into the resampled leverage processes, we use a specification that allows for time-varying targets. In this case, the target leverage depends on the initial leverage of a firm and is periodically changed by observed equity returns and resampled issuances. The true SOA is set to some fixed value, different from 0 , generating simulated leverage paths with adjustment. Note that the regressions are based on the true target leverage as an exogenous regressor, such that any biases do not arise from potential problems of estimating determinants of target leverage. Table 4 contains summary statistics of simulated data.

TABLE 4

Average Sample Statistics for Resampled Leverage Data

Table 4 presents the average sample statistics for the resampled leverage process in Section III.B.2. Resampling is based on firms' actual equity and debt changes, using an algorithm similar to the one suggested by lliev and Welch (2010). "Mean" stands for the mean value of all observations of the variable for the respective choice of the true SOA $\lambda$. The standard deviation of the variable is in parentheses. The table also contains the relative number of market debt ratio observations that are both equal to $0\left(\mathrm{Obs}\left(\mathrm{LEV}_{i t}=0\right)\right)$ and equal to $1\left(\mathrm{Obs}\left(\mathrm{LEV}_{i t}=1\right)\right)$.

\begin{tabular}{|c|c|c|c|c|c|c|}
\hline True $\lambda$ & -0.2 & 0.0 & 0.2 & 0.3 & 0.5 & 0.8 \\
\hline Mean $\left(\mathrm{LEV}_{i t}\right)$ & $\begin{array}{c}0.388 \\
(0.410)\end{array}$ & $\begin{array}{c}0.293 \\
(0.327)\end{array}$ & $\begin{array}{c}0.240 \\
(0.267)\end{array}$ & $\begin{array}{c}0.229 \\
(0.256)\end{array}$ & $\begin{array}{c}0.215 \\
(0.246)\end{array}$ & $\begin{array}{c}0.202 \\
(0.245)\end{array}$ \\
\hline $\operatorname{Obs}\left(\operatorname{LEV}_{i t}=0\right)$ & 0.276 & 0.273 & 0.271 & 0.275 & 0.288 & 0.312 \\
\hline $\operatorname{Obs}\left(\operatorname{LEV}_{i t}=1\right)$ & 0.215 & 0.038 & 0.008 & 0.006 & 0.005 & 0.005 \\
\hline
\end{tabular}

We analyze the set of estimators used in the previous sections, but in addition include the so-called W estimator (Iliev and Welch (2010), Welch (2004)). ${ }^{22}$ Figure 3 shows the simulation results, and Table 5 summarizes the corresponding average bias of the estimators.

All benchmark estimators are severely biased as in the prior experiments. The long difference estimator underestimates for fast and overestimates for slow adjustment, and the Blundell-Bond (1998) estimator overestimates up to a true $\lambda$ of about 0.8 . The LSDVC estimator performs worst, for example, finding an adjustment speed of $20 \%$ for a 0 true adjustment speed. The $\mathrm{W}$ estimator and DPF estimator are least biased and yield estimates of less than $10 \%$, if there is 0

(zero debt in $t+1$ divided by zero debt in $t$ ) or are infinite (nonzero debt in $t+1$ divided by zero debt in $t$ ). A detailed description of the applied algorithm is given in Internet Appendix C.

${ }^{22}$ The regression specification of the $\mathrm{W}$ estimator, which is applicable only in this specific capital structure setting, is

$$
\mathrm{LEV}_{i, t+1}=c+\lambda \mathrm{LEV}_{i t}+(1-\lambda) \mathrm{IDR}_{i, t, t+1}+\left[\gamma \mathrm{LEV}_{i, t+1}^{*}\right]+u_{i, t+1}
$$

where $\mathrm{IDR}_{i, t, t+1}=D_{i t} /\left(D_{i t}+\left(1+r_{t, t+1}\right) E_{i t}\right)$ is the implied debt ratio that results if the firm issues neither debt nor equity, that is, a stock-return-only induced debt ratio. The SOA in this specification is 1 minus the estimate on the IDR coefficient. 
FIGURE 3

\section{Bias Curves for Resampled Leverage Data}

Figure 3 shows the average estimates of the SOA $\lambda$, which corresponds to 1 minus the coefficient on the lagged dependent variable. Debt ratio data are generated according to the partial adjustment model described in equations (6) and (7), using debt and equity changes from the Compustat sample described in Section IV.A. The horizontal axis shows the true parameter in the simulation and the vertical axis, the corresponding estimated coefficient. Results are reported for different estimators: pooled OLS ("OLS"), Fama-MacBeth regressions ("FamaMac") (1973), fixed effects ("FixEff"), Blundell-Bond ("BlunBo") (1998), long difference ("LD"), LSDVC ("LSDVC"), the W estimator ("W") and the DPF estimator suggested in Section III.A.1 ("DPF"). The number of Monte Carlo replications is 500, where the number of firms is 16,170 and of firmyears is 166,016 for each run. The first observed debt ratio for each firm in the sample is always the initial condition in the data-generating process for each simulation run. Simulation results are shown where the true target leverage is included as an independent variable in the regression specifications.

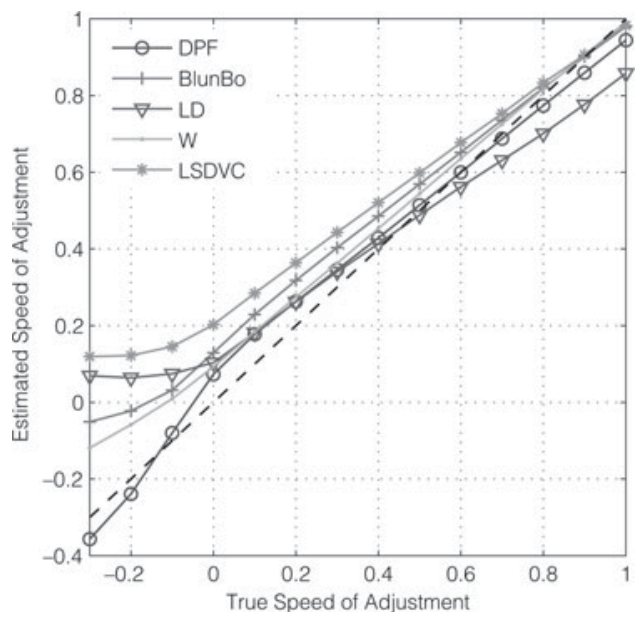

TABLE 5

Average Bias of Estimators for Resampled Leverage Data

Table 5 presents the average bias (estimated value - true value) for each estimator for different adjustment speeds $\lambda$ from the resampling results shown in Figure 3. Resampling is based on firms' actual equity and debt changes, using an algorithm similar to the one suggested by lliev and Welch (2010).

\begin{tabular}{|c|c|c|c|c|c|c|}
\hline True $\lambda$ & -0.2 & 0.0 & 0.2 & 0.3 & 0.5 & 0.8 \\
\hline DPF & -0.039 & 0.073 & 0.063 & 0.046 & 0.014 & -0.026 \\
\hline Blundell-Bond & 0.178 & 0.129 & 0.118 & 0.103 & 0.069 & 0.020 \\
\hline Long difference & 0.264 & 0.104 & 0.062 & 0.040 & -0.012 & -0.099 \\
\hline W & 0.142 & 0.093 & 0.074 & 0.063 & 0.044 & 0.017 \\
\hline LSDVC & 0.322 & 0.203 & 0.164 & 0.144 & 0.098 & 0.033 \\
\hline
\end{tabular}

true adjustment, whereas all other methods overestimate by a minimum of $10 \%$ (long difference) up to a maximum of $20 \%$ (LSDVC). ${ }^{23}$

We conduct further (unreported) simulations in which the target leverage is not perfectly observed, which is most likely the case in applied empirical work. Even in situations where the target is i) not known, ii) measured with an error, or iii) we include an irrelevant target, the DPF estimator remains the least biased estimator.

\footnotetext{
${ }^{23}$ Note that for decreasing negative true speeds of adjustment, the benchmark estimators yield almost flat or nondecreasing estimation curves. Only the W estimator and the DPF estimator show a decreasing pattern, as they should.
} 


\section{Further Robustness Tests of the DPF Estimator}

\section{Easy Work-Arounds for Fractionality}

Some studies attempt to use easy work-arounds in order to solve the problem of fractional debt ratios. For example, most of these studies report that their results are robust, even if they omit all 0 debt ratio observations or all observations smaller than $10 \%$. This is bascially what we find for the bias curves of the benchmark estimators, if we check the robustness of our results. The bias curves of these estimators essentially do not change if we drop i) all 0 debt ratio observations, ii) all debt ratio observations equal to 1 , iii) all debt ratio observations equal to 0 or 1 , or iv) all debt ratios smaller than $10 \% .{ }^{24}$ However, no change implies that the severe bias remains, rendering easy work-arounds infeasible for handling the issue of a fractional dependent variable.

Intuitively, there is no change in bias after easy work-arounds, as one does not solve the "mechanical mean reversion" problem by dropping censored observations, that is, the data still never exceed the boundaries (and remain censored, now at different levels) such that standard estimators attribute this to different degrees of mean reversion and remain biased. In statistical terms, discarding limit observations even has the potential to increase econometric problems as one essentially truncates the data. As discussed, for example, by Greene ((2011), p. 879), truncation biases regression estimates similar to an omitted variables problem. Moreover, omitting observations may result in a loss of important information on the latent variable's distribution and its dynamic evolution.

Another potential work-around to deal with observations at the limit of 0 is to use total liabilities instead of only interest-bearing debt to measure leverage. The corresponding total-liabilities-to-total-assets ratio (LT_AT) is thus financial debt plus nonfinancial liabilities divided by total book assets. Using LT_AT will reduce the frequency of 0 leverage observations, but it ignores differences between nonfinancial liabilities and financial leverage. However, this work-around does not solve the fractionality issue in principle, because values are still limited between 0 and $1 .{ }^{25}$ The benefit of changing the measure is that leverage is shifted by some average value, and a large reduction in the frequency of observations at the observed limits occurs in the actual data (unreported). When we conduct Monte Carlo simulations similar to those reported in Section III and adjust the data-generating process to resemble the empirical distribution of LT_AT, we still find severe bias of common estimators, in particular when the true SOA is close to 0 .

\section{Misspecification of Target Leverage}

In Section III.A.3 we show that the DPF estimator remains unbiased even if the data are not actually censored. However, one potential disadvantage of the DPF estimator is the requirement of a parametric specification of the fixed

\footnotetext{
${ }^{24}$ The results of this subsection are untabulated for brevity but are available from the authors upon request.

${ }^{25} \mathrm{Also}$, it is not obvious whether a measure of leverage incorporating nonfinancial liabilities is suitable for the analysis of dynamic capital structure adjustment (Welch (2011)).
} 
effects distribution. Since this distribution is unknown in reality, it is important to test the robustness of the estimator against corresponding misspecifications.

The first misspecification we consider is overspecification of the model. One fundamental problem of applied empirical work is to determine the set of explanatory variables to be included in the regression model. In the context of capital structure research, some variables are suggested by economic theory, but most empirical designs are driven by empirical findings in previous studies. Since it is well known that an omitted variables bias can seriously affect almost all estimators, a cautious researcher might include more explanatory variables into her design than predicted by theory or previous evidence, so as to avoid omitting a relevant determinant of the data-generating process (this inevitably sacrifices some of the estimator's efficiency).

Panel A of Table 6 gives the results for one such case of over-specification in the setting of our Monte Carlo design for fractional dependent variables. Here it is assumed that the researcher includes a second explanatory variable in the regression specification, which under the true data-generating process is irrelevant. This does not change the properties of standard estimators, since this type of misspecification affects only their efficiency. In the case of the DPF estimator, however, a superfluous regressor might have serious consequences, because the model's misspecification directly enters the presumed fixed effects distribution.

\section{TABLE 6}

Average Bias of Estimators with Misspecified Regressors

\begin{tabular}{|c|c|c|c|c|c|c|}
\hline True $\lambda$ & -0.2 & 0.0 & 0.2 & 0.3 & 0.5 & 0.8 \\
\hline \multicolumn{7}{|c|}{ Panel A. Irrelevant Regressor } \\
\hline $\begin{array}{l}\text { DPF } \\
\text { Blundell-Bond } \\
\text { Long difference } \\
\text { LSDVC }\end{array}$ & $\begin{array}{r}-0.012 \\
0.168 \\
0.334 \\
0.327\end{array}$ & $\begin{array}{r}-0.001 \\
-0.009 \\
0.163 \\
0.165\end{array}$ & $\begin{array}{r}0.011 \\
-0.090 \\
0.060 \\
0.065\end{array}$ & $\begin{array}{r}0.014 \\
-0.074 \\
0.044 \\
0.057\end{array}$ & $\begin{array}{l}0.011 \\
0.029 \\
0.044 \\
0.055\end{array}$ & $\begin{array}{l}0.007 \\
0.053 \\
0.039 \\
0.045\end{array}$ \\
\hline \multicolumn{7}{|c|}{ Panel B. Omitted Target } \\
\hline $\begin{array}{l}\text { DPF } \\
\text { Blundell-Bond } \\
\text { Long difference } \\
\text { LSDVC }\end{array}$ & $\begin{array}{r}-0.003 \\
0.164 \\
0.333 \\
0.332\end{array}$ & $\begin{array}{r}-0.001 \\
-0.009 \\
0.162 \\
0.167\end{array}$ & $\begin{array}{r}0.001 \\
-0.086 \\
0.060 \\
0.071\end{array}$ & $\begin{array}{r}-0.001 \\
-0.077 \\
0.047 \\
0.071\end{array}$ & $\begin{array}{r}-0.004 \\
0.032 \\
0.052 \\
0.065\end{array}$ & $\begin{array}{r}-0.006 \\
0.069 \\
0.045 \\
0.051\end{array}$ \\
\hline
\end{tabular}

In the simulations underlying Table 6, we assume that the regressions include a second exogenous variable with a positive mean and correlation with the other exogenous variable $X_{i t}$, which is a component of the true data-generating process. For simplicity, we have modeled this superfluous variable as the squared value of $X_{i t}$. As Table 6 shows (Panel A), the DPF estimator still yields almost unbiased estimates for the SOA, compared to Table 2, indicating the robustness of the DPF estimator in this situation as well. The bias of the DPF estimator continues to be virtually 0 (the significant bias of the benchmark estimators remains unchanged as well).

Another misspecification with respect to target leverage arises if a determinant of the data-generating process is omitted from the specification. Panel B of 
Table 6 contains the change in absolute adjustment speed bias, if the exogenous regressor $X_{i t}$ determining the target leverage is omitted from the regression specification. Note that this is not comparable to a general situation with an "omitted variables" problem, since the lagged debt ratio implicitly contains information on the history of prior debt ratios and target values, which in principle allows unbiased estimation. ${ }^{26}$ The situation might nevertheless be problematic for the DPF estimator because of the misspecification of the fixed effects distribution in the estimation. Yet, as shown in Table 6, the DPF estimator remains unbiased, as does the bias of all other estimators. Thus, the omitted target determinant in the regressions causes only minor problems for the estimation of the coefficient on the lagged dependent variable.

\section{Violation of Normally Distributed Error Terms}

Unlike the benchmark estimators Blundell-Bond (1998), long difference, and LSDVC, the DPF estimator is a maximum likelihood estimator and thus requires the specification of a distribution of the error terms for obtaining coefficient estimates. Maximizing the likelihood function based on an incorrect error term distribution, that is, if the assumed distribution differs from the actual one in the data, is called quasi-maximum likelihood estimation. A quasi-maximum likelihood estimator can be biased.

The DPF estimator assumes normally distributed error terms $u_{i t} \sim N\left(0, \sigma_{u}^{2}\right)$ and fixed effects errors $a_{i} \sim N\left(0, \sigma_{a}^{2}\right)$ for its maximum likelihood estimation. In this section we test the robustness of the DPF estimator to violations in the assumed normality of the error distributions. For this we run further Monte Carlo simulations based on the data-generating process described in Section III.A.1 but change the error terms and fixed effects errors distributions.

We closely follow Bollerslev and Wooldridge (1992) to examine the robustness of the DPF estimator in a quasi-maximum likelihood setting. To generate nonnormal error term distributions, we generate the data using a symmetric $t$-distribution (with three degrees of freedom, to examine fat tails) and an asymmetric $\chi^{2}$-distribution (to examine a skewed distribution). Table 7 contains the bias of estimators for different error term distributions. Panel A presents the results for $t$-distributed error terms $u_{i t}=\xi_{i t}\left(\sigma_{U} / \sqrt{3}\right)$, where $\xi_{i t} \sim t(3)$. The DPF estimator exhibits a very small bias for 0 and negative adjustment speeds but remains unbiased for adjustment speeds larger than 0 . The benchmark estimators do not change their bias curves for $t$-distributed error terms (i.e., they remain as biased as with normal error terms). Panel B presents the simulation results for $\chi^{2}$-distributed error terms $u_{i t}=\left(\left(\xi_{i t}-1\right) \sqrt{2}\right) \sigma_{U}$, where $\xi_{i t} \sim \chi^{2}(1)$. The DPF estimator remains unbiased for asymmetric error terms. ${ }^{27}$

Finally, in unreported tests we also analyze $t$ - or $\chi^{2}$-distributed fixed effects but do not find any notable changes in the bias curves for the DPF or the other

\footnotetext{
${ }^{26}$ Since under the partial adjustment process leverage is autoregressive, target leverage will be identified even if one does not include additional explanatory variables that proxy for the unknown targets.

${ }^{27}$ Comparing bias results of Table 2 to Table 7 for the benchmark estimators shows that a small increase in bias for 0 and small positive adjustment speeds results only for the Blundell-Bond (1998) estimator.
} 
TABLE 7

Average Bias of Estimators with Nonnormal Error Terms

Table 7 presents the average bias (estimated value - true value) of different estimators based on Monte Carlo simulations using the data-generating process of the DPF estimator with censored dependent variable, but with different error term distributions. Since estimation of the DPF assumes normally distributed errors (while Blundell-Bond (1998), long difference, and LSDVC do not), this is a misspecification test for the DPF estimator. Columns show average bias under varying specifications of the true SOA $\lambda$. Panel A contains the results for symmetric ( $t$-distributed) error terms. Panel B includes the results for asymmetric ( $\chi^{2}$-distributed) error terms.

\begin{tabular}{|c|c|c|c|c|c|c|}
\hline True $\lambda$ & -0.2 & 0.0 & 0.2 & 0.3 & 0.5 & 0.8 \\
\hline \multicolumn{7}{|c|}{ Panel A. Symmetric (t-distributed) } \\
\hline $\begin{array}{l}\text { DPF } \\
\text { Blundell-Bond } \\
\text { Long difference } \\
\text { LSDVC }\end{array}$ & $\begin{array}{r}-0.004 \\
0.149 \\
0.330 \\
0.319\end{array}$ & $\begin{array}{r}-0.004 \\
-0.046 \\
0.150 \\
0.146\end{array}$ & $\begin{array}{r}-0.008 \\
-0.114 \\
0.047 \\
0.053\end{array}$ & $\begin{array}{r}-0.008 \\
-0.081 \\
0.032 \\
0.043\end{array}$ & $\begin{array}{r}-0.005 \\
0.026 \\
0.019 \\
0.047\end{array}$ & $\begin{array}{r}-0.002 \\
0.046 \\
0.043 \\
0.044\end{array}$ \\
\hline \multicolumn{7}{|c|}{ Panel B. Asymmetric ( $\chi^{2}$-distributed) } \\
\hline $\begin{array}{l}\text { DPF } \\
\text { Blundell-Bond } \\
\text { Long difference } \\
\text { LSDVC }\end{array}$ & $\begin{array}{r}-0.024 \\
0.166 \\
0.328 \\
0.330\end{array}$ & $\begin{array}{r}-0.020 \\
-0.013 \\
0.157 \\
0.163\end{array}$ & $\begin{array}{r}-0.002 \\
-0.094 \\
0.054 \\
0.063\end{array}$ & $\begin{array}{r}-0.003 \\
-0.080 \\
0.041 \\
0.053\end{array}$ & $\begin{array}{r}-0.004 \\
0.021 \\
0.040 \\
0.053\end{array}$ & $\begin{array}{r}-0.001 \\
0.051 \\
0.042 \\
0.046\end{array}$ \\
\hline
\end{tabular}

benchmark estimators. Thus, the DPF estimator is fairly robust to the analyzed violations of the normal distribution assumptions, which alleviates some concerns due to the DPF estimator being a maximum likelihood estimator.

\section{Adjustment toward Target Leverage Revisited}

In the previous section we extensively tested estimators typically applied for adjustment speed estimation in corporate finance and showed that only the DPF estimator is unbiased in the presence of fractionality of the (lagged) dependent variable, unobserved heterogeneity, and unbalanced panel data. The estimator is also robust to the "mechanical mean reversion" problem and always provides unique estimates of the SOA for different true underlying adjustment speeds. In light of these results, we revisit the empirical evidence on leverage adjustment and apply the DPF estimator to the typical Compustat sample, to compare our results with previous research.

Graham and Leary (2011) argue in their survey article that testing capital structure adjustments for the whole economy has limited informative value since it assumes that all firms have the same adjustment costs. Instead, one might want to compare subsamples of firms with potentially different adjustment costs to learn about the economic relevance of adjustment behavior. We show that the DPF and the Blundell-Bond (1998) estimator lead to very different conclusions regarding SOA of subsamples of firms (illustrated by analyzing firm groups with different issuer rating by $\mathrm{S} \& \mathrm{P}$ ), in spite of both estimators yielding similar estimates for the full sample of Compustat firms.

\section{A. Data}

The regression model is the partial adjustment specification in equation (3),

$$
\mathrm{LEV}_{i, t+1}=\lambda\left(\boldsymbol{X}_{i t} \boldsymbol{\gamma}\right)+(1-\lambda) \mathrm{LEV}_{i t}+c_{i}+\epsilon_{i, t+1}
$$


The vector of firm characteristics $\boldsymbol{X}_{i t}$ determining target leverage $\mathrm{LEV}_{i, t+1}^{*}=\boldsymbol{X}_{i t} \boldsymbol{\gamma}$ follows the one in Flannery and Rangan (2006). Definitions of these variables and summary statistics can be found in Table 8.

\section{TABLE 8}

\section{Summary Statistics for Compustat Data}

The sample consists of industrial Compustat firms with complete data for 2 or more consecutive years during 1965-2009. The number of firms is 16,357 and of firm-years is, 169,787. The market debt ratio ( LEV $_{i t}$ ) is not winsorized. All other variables are winsorized at the 1st and 99th percentiles. The table also contains the absolute (and relative) number of market debt ratio observations that are both equal to $0\left(\mathrm{Obs}\left(\mathrm{LEV}_{i t}=0\right)\right)$ and equal to $1\left(\mathrm{Obs}\left(\mathrm{LEV}_{i t}=1\right)\right)$. Moreover, the $99 \%$ quantile of the market debt ratio distribution is provided. Codes in brackets denote Compustat items:

Market debt ratio $\left(\mathrm{LEV}_{i t}\right)$ : Book value of debt divided by the market value of assets (book value of debt plus market value of equity). ((Long-Term Debt [DLTT] + Debt in Current Liabilities [DLC]) / (Long-Term Debt [DLTT] + Debt in Current Liabilities [DLC] + Price Fiscal Year Close [PRCC_F] $\times$ Common Shares Outstanding [CSHO])).

Book debt ratio (BDR): Book debt divided by total assets. ((Long-Term Debt [DLTT] + Debt in Current Liabilities [DLC]) / Total Assets [AT])

Profitability (EBIT_TA): Earnings before interest and taxes divided by total assets. ((Income Before Extraordinary Items $[\mathrm{IB}]+$ Interest Expense [XINT] + Income Taxes [TXT]) / Total Assets [AT]).

Market-to-book (MB): Market-to-book ratio of firm assets. ((Long-Term Debt [DLTT] + Debt in Current Liabilities [DLC] + Preferred Stock $[\mathrm{PSTKL}]+$ Price Fiscal Year Close $\left[\mathrm{PRCC} \_\right.$F] $\times$Common Shares Outstanding [CSHO]) / Total Assets $[A T])$.

Depreciation/Taxes (DEP_TA): Depreciation expense divided by total assets. (Depreciation and Amortization [DP] / Total Assets $[A T])$

Size $(\operatorname{In}(T A))$ : Natural logarithm of total assets. $(\operatorname{In}($ Total Assets [AT] × 1,000,000) measured in 1983 dollars, deflated by the consumer price index).

Asset Tangibility (FA_TA): Fixed assets divided by total assets. (Property, Plant, and Equipment [PPENT] / Total Assets $[\mathrm{AT}])$.

No R\&D (R\&D DUM): Dummy variable equaling 1 for missing R\&D expenses.

R\&D expenses (R\&D_TA): R\&D expense divided by total assets. (Research and Development Expense [XRD] / Total Assets [AT]).

Industry Median Leverage (Ind_Median): Median market debt ratio of firm i's Fama and French (1997) industry classification at time $t$

Rating (Rated): (Debt market access) Dummy variable equaling 1 for firms with public debt rating. (S\&P LT Domestic Issuer Credit Rating [SPLTICRM])

Market debt ratio $\left(\mathrm{LEV}_{i t}\right)$

Book debt ratio (BDR)

Profitability (EBIT_TA)

Market-to-book (MB)

Depreciation/Taxes (DEP_TA)

Size $(\operatorname{In}(T A))$

Asset tangibility (FA_TA)

No R\&D (R\&D_DUM)

R\&D expenses (R\&D_TA)

Industry median leverage (Ind_Median)

Rating (Rated)

No. of obs. Market debt ratio $=0$

No. of obs. Market debt ratio $=1$

99\%-Quantile market debt ratio

\begin{tabular}{|c|c|c|c|c|}
\hline Mean (Relative) & Median & Std. Dev. & Min. & Max. \\
\hline 0.2682 & 0.2045 & 0.2496 & 0.0000 & 1.0000 \\
\hline 0.2453 & 0.2228 & 0.1985 & 0.0000 & 0.8168 \\
\hline 0.0036 & 0.0812 & 0.3076 & -1.8079 & 0.3754 \\
\hline 1.6855 & 1.0522 & 2.0020 & 0.2729 & 14.0244 \\
\hline 0.0469 & 0.0384 & 0.0367 & 0.0005 & 0.2282 \\
\hline 23.0928 & 22.8632 & 2.3725 & 18.4294 & 29.2259 \\
\hline 0.3089 & 0.2587 & 0.2269 & 0.0016 & 0.9032 \\
\hline 0.4594 & 0.0000 & 0.4984 & 0.0000 & 1.0000 \\
\hline 0.0462 & 0.0000 & 0.3910 & 0.0000 & 131.5000 \\
\hline 0.2245 & 0.2219 & 0.1351 & 0.0071 & 0.5794 \\
\hline 0.1298 & 0.0000 & 0.3361 & 0.0000 & 1.0000 \\
\hline $\begin{array}{r}18,172(10.70 \%) \\
38(0.02 \%) \\
0.9188\end{array}$ & & & & \\
\hline
\end{tabular}

The sample consists of Compustat firms with complete data for 2 or more consecutive years during the period 1965-2009. Firms from the financial industry (Standard Industrial Classification (SIC) 6000-6999), regulated utilities (SIC 4900-4999), and firm-years with a negative book value of equity are excluded. No firm size restrictions are imposed. The sample comprises 16,357 firms with 169,787 firm-years. All variables, except the market debt ratio $\mathrm{LEV}_{i t}$, are winsorized at the 1st and 99th percentiles. For regression variables that are not ratios, nominal values are expressed in 1983 dollars, using the consumer price index as a deflator. About $11 \%$ of all (unwinsorized) market debt ratio observations are at 0 , the lower limit of the potential market debt ratio range. Only $0.02 \%$ of all market debt ratios are at the upper limit of 1 . The $99 \%$ quantile of market debt ratios is roughly at $92 \%$. 
For brevity, we report only the SOA estimates and omit coefficients on explanatory variables in the following analyses. ${ }^{28}$

\section{B. Full Sample Adjustment Speed}

Table 9 contains the SOA estimates for the standard partial adjustment model. More than 18,000 firm-years (about $11 \%$ of all observations) have a market or book debt ratio of 0 and there are a few observations with ratios equal to 1 . The debt ratio is clearly fractional. Taking this fractionality explicitly into account, the DPF estimator (column 1 of Panel A) yields an SOA estimate of 26\% for market debt ratios. The associated half-life of leverage shocks is 2.27 years. This result is in the middle of the range of adjustment speeds reported in previous studies (see Huang and Ritter (2009), Tab. 8).

\section{TABLE 9}

\section{Comparison of Speed of Adjustment for Different Estimation Methods for Compustat Data}

Table 9 presents regression results for the partial adjustment model of Flannery and Rangan (2006):

$$
\mathrm{LEV}_{i, t+1}=(\lambda \boldsymbol{\gamma}) \boldsymbol{X}_{i t}+(1-\lambda) \mathrm{LEV}_{i t}+c_{i}+\epsilon_{i, t+1}
$$

where $\lambda$ is the SOA coefficient from the lagged market debt ratio $\left(\mathrm{LEV}_{i t}=\mathrm{MDR}_{i t}\right)$ or book debt ratio $\left(\mathrm{LEV}_{i t}=\mathrm{BDR}_{i t}\right), c_{j}$ is a time-invariant unobserved variable (firm fixed effect), and $\epsilon_{i, t+1}$ is an error term. The (lagged) variables $\left(\boldsymbol{X}_{i t}\right)$ determining a firm's long-run target leverage are described in Section IV and Table 8. $t$-statistics are reported in parentheses. ${ }^{* *},{ }^{* \star}$, and * denote coefficients statistically significantly different from 0 at the $1 \%, 5 \%$, and $10 \%$ levels, respectively. The implied half-life is calculated as $[\log (0.5) / \log (1-\lambda)]$. The observation period is $1965-2009$. In this period, 18,172(10.70\%) LEV observations are equal to 0 and $38(0.02 \%) L^{2} V_{i t}$ observations are equal to 1.

\begin{tabular}{|c|c|c|c|c|c|c|c|c|}
\hline & $\begin{array}{c}\text { DPF } \\
1 \\
\end{array}$ & $\begin{array}{c}\text { Fixed } \\
\text { Effects } \\
2 \\
\end{array}$ & $\begin{array}{l}\text { IV Fixed } \\
\text { Effects } \\
3\end{array}$ & $\begin{array}{c}\text { Pooled OLS } \\
4 \\
\end{array}$ & $\begin{array}{l}\text { Fama- } \\
\text { MacBeth } \\
5 \\
\end{array}$ & $\begin{array}{c}\text { Blundell- } \\
\text { Bond } \\
6 \\
\end{array}$ & $\begin{array}{c}\text { Long } \\
\text { Difference } \\
7 \\
\end{array}$ & $\begin{array}{l}\text { LSDVC } \\
8 \\
\end{array}$ \\
\hline \multicolumn{9}{|c|}{ Panel A. Lagged MDR } \\
\hline & $\begin{array}{c}0.737^{* \star *} \\
(269.43)\end{array}$ & $\begin{array}{c}0.609^{\star \star \star} \\
(263.05)\end{array}$ & $\begin{array}{c}0.650^{\star \star \star} \\
(200.61)\end{array}$ & $\begin{array}{c}0.848^{* * *} \\
(436.11)\end{array}$ & $\begin{array}{l}0.855^{\star \star \star} \\
(72.86)\end{array}$ & $\begin{array}{c}0.744^{\star \star \star} \\
(373.11)\end{array}$ & $\begin{array}{c}0.779^{* \star \star} \\
(196.80)\end{array}$ & $\begin{array}{c}0.726^{\star \star \star} \\
(218.92)\end{array}$ \\
\hline $\begin{array}{l}\text { Implied SOA } \lambda \\
\text { Implied half-life }\end{array}$ & $\begin{array}{c}26.3 \% \\
2.27 \text { years }\end{array}$ & $\begin{array}{l}39.1 \% \\
1.40 \text { years }\end{array}$ & $\begin{array}{c}35.0 \% \\
1.61 \text { years }\end{array}$ & $\begin{array}{c}15.2 \% \\
4.20 \text { years }\end{array}$ & $\begin{array}{c}14.5 \% \\
4.42 \text { years }\end{array}$ & $\begin{array}{c}25.6 \% \\
2.34 \text { years }\end{array}$ & $\begin{array}{c}22.1 \% \\
2.78 \text { years }\end{array}$ & $\begin{array}{c}27.4 \% \\
2.16 \text { years }\end{array}$ \\
\hline \multicolumn{9}{|c|}{ Panel B. Lagged BDR } \\
\hline & $\begin{array}{c}0.727^{\star \star \star} \\
(265.94)\end{array}$ & $\begin{array}{c}0.581^{\star \star \star} \\
(248.48)\end{array}$ & $\begin{array}{c}0.633^{\star \star \star} \\
(193.24)\end{array}$ & $\begin{array}{c}0.832^{\star \star \star} \\
(376.30)\end{array}$ & $\begin{array}{c}0.840^{\star \star \star} \\
(145.94)\end{array}$ & $\begin{array}{c}0.698^{\star \star \star} \\
(295.92)\end{array}$ & $\begin{array}{c}0.786^{\star \star \star} \\
(210.56)\end{array}$ & $\begin{array}{c}0.686^{* \star \star} \\
(222.83)\end{array}$ \\
\hline $\begin{array}{l}\text { Implied SOA } \lambda \\
\text { Implied half-life }\end{array}$ & $\begin{array}{l}27.3 \% \\
2.17 \text { years }\end{array}$ & $\begin{array}{c}41.9 \% \\
1.28 \text { years }\end{array}$ & $\begin{array}{c}36.7 \% \\
1.51 \text { years }\end{array}$ & $\begin{array}{c}16.8 \% \\
3.77 \text { years }\end{array}$ & $\begin{array}{c}16.0 \% \\
3.96 \text { years }\end{array}$ & $\begin{array}{c}30.2 \% \\
1.92 \text { years }\end{array}$ & $\begin{array}{c}21.4 \% \\
2.88 \text { years }\end{array}$ & $\begin{array}{c}31.4 \% \\
1.84 \text { years }\end{array}$ \\
\hline No. of firm-years & 169,787 & 169,787 & 169,787 & 169,787 & 169,787 & 169,787 & 87,631 & 169,787 \\
\hline
\end{tabular}

Panel A of Table 9 contains the regression results for market debt ratios. Fairly high speeds of adjustment are estimated by means of the within-fixedeffects estimator (39.1\%, column 2) and the instrumental variables (IV) fixed effects estimator (35.0\%, column 3) introduced by Flannery and Rangan (2006). The latter estimator uses book debt ratios as instruments for lagged market debt ratios. ${ }^{29}$ Much slower adjustment speeds are estimated by pooled OLS (15.2\%, column 4) and Fama-MacBeth (1973) (14.5\%, column 5).

\footnotetext{
${ }^{28}$ With respect to estimation results, coefficient estimates using the DPF estimator are very similar to the corresponding results by Flannery and Rangan (2006), except for the coefficient on the lagged market debt ratio (of course). These estimates can be found in Internet Appendix D.

${ }^{29}$ Note that it is not clear that the identifying restriction is satisfied using lagged book value debt ratios.
} 
The Blundell-Bond (1998) (25.6\%, column 6 of Table 9), the long difference $\left(22.1 \%\right.$, column 7) GMM estimators, and the LSDVC estimator ${ }^{30}(27.4 \%$, column 8) yield similar adjustment speeds as the DPF estimator in this particular sample. The corresponding regression results for book debt ratios are given in Panel B. Similar to Flannery and Rangan (2006) and Huang and Ritter (2009), there are no notable differences between book- and market-debt-ratio-based adjustment speeds. Adjustment speeds for market debt ratios are just slightly slower than for book debt ratios except for the long difference estimator. These small differences could be caused by mechanistic stock price changes as found by Welch (2004). However, Rangan translate Welch's regression approach into the partial adjustment model and do not find support for Welch's (2004) hypothesis.

In our simulation and resampling experiments in Section III, we show that the DPF estimator is the only estimator that always gives unique estimates of the SOA. Without knowing the corresponding DPF estimate, it is difficult to say whether the Blundell-Bond (1998) and long difference estimates indicate completely different adjustment speeds (and thus economic implications) since they might yield the same adjustment speed for different underlying true adjustment speeds.

\section{Comparing Subsample Adjustment Speeds}

In the previous section the DPF SOA is similar to the Blundell-Bond (1998) estimate for the full Compustat sample. As we know from the bias curves in Figures 2 and 3, the two estimators can have very different results, varying with true adjustment speeds. To compare subsample adjustment speeds, it is necessary to apply an estimator that always gives unique estimates of the SOA.

We demonstrate that the two estimators can lead to very different conclusions about SOA by analyzing subsamples of rated firms. We expect adjustment speeds to vary between rated and unrated firms and between different rating categories (Kisgen (2006), (2009)). Rated firms (and low default risk firms) will have better access to external capital markets, allowing a higher SOA. However, rated firms with higher debt capacities (either due to accessibility or low default risk) will also have lower opportunity costs of deviating from target leverage, which implies a lower SOA. ${ }^{31}$ The net effect is unclear, but SOA will likely be heterogeneous in subsamples.

Table 10 presents corresponding results, comparing SOA estimates between firms grouped by rating categories. ${ }^{32}$ Firms are classified by their average rating over all firm-years with an S\&P issuer rating available. ${ }^{33}$ The design of the

\footnotetext{
${ }^{30}$ The xtlsdvc Stata command provided by Bruno (2005b) and used by Flannery and Hankins (2013) is designed for small panel data sets. It is almost inapplicable to large data sets $(>20,000$ observations) as only bootstrapped standard errors are unbiased and a single estimation of the partial adjustment model for the full Compustat data set takes more than 20 hours on a fast PC. Therefore, we have devised a fast and accurate Matlab implementation that handles large data sets. Reported LSDVC standard errors in Table 9 are derived from 500 bootstrap replications.

${ }^{31}$ Faulkender et al. (2012) and Elsas and Florysiak (2011) provide a more detailed discussion of heterogeneity in the expected cost of deviation from target debt ratios.

${ }^{32}$ More details on the DPF estimation in this case can be found in Elsas and Florysiak (2011).

${ }^{33}$ Grouping on average ratings introduces some selection and entails the danger of misclassification at some periods of time, because firms with high ratings in most periods can nevertheless become
} 
TABLE 10

Heterogeneity in Speed of Adjustment for Firm Subsamples Grouped by Their Average Rating

Table 10 presents conditional regression results for the partial adjustment model of Flannery and Rangan (2006):

$$
\operatorname{LEV}_{i, t+1}=(\lambda \boldsymbol{\gamma}) \boldsymbol{X}_{i t}+(1-\lambda) \operatorname{LEV}_{i t}+c_{i}+\epsilon_{i, t+1}
$$

where $\lambda$ is the adjustment speed coefficient on the lagged market debt ratio (LEV $\left.V_{i t}\right), c_{i}$ is a time-invariant unobserved variable (firm fixed effect), and $\epsilon_{i, t+1}$ is an error term. The (lagged) variables determining a firm's long-run target leverage are described in Section IV and Table 8. Standard errors are reported in parentheses. Results are reported for the BlundellBond (1998) estimator and the DPF estimator suggested in Section III.A.1. Only the implied SOA $\lambda$ is reported. All other coefficient estimates, including year dummies, are omitted. Each subsample consists of firms belonging to the respective rating category on average, for all available firm data in Compustat. "All rated" stands for the subsample of rated firms. "All unrated" stands for the subsample of unrated firms.

\begin{tabular}{|c|c|c|c|c|}
\hline & DPF & Blundell-Bond & No. of Firm-Years & No. of Firms \\
\hline AAA to AA - & $\begin{array}{c}0.295 \\
(0.027)\end{array}$ & $\begin{array}{c}0.295 \\
(0.106)\end{array}$ & 1,355 & 86 \\
\hline$A+$ to $A-$ & $\begin{array}{c}0.151 \\
(0.012)\end{array}$ & $\begin{array}{c}0.318 \\
(0.009)\end{array}$ & 3,980 & 293 \\
\hline $\mathrm{BBB}+$ to $\mathrm{BBB}-$ & $\begin{array}{c}0.166 \\
(0.018)\end{array}$ & $\begin{array}{c}0.322 \\
(0.004)\end{array}$ & 5,929 & 516 \\
\hline $\mathrm{BB}+$ to $\mathrm{B}-$ & $\begin{array}{c}0.141 \\
(0.009)\end{array}$ & $\begin{array}{c}0.292 \\
(0.000)\end{array}$ & 10,166 & 1,592 \\
\hline $\mathrm{CCC}+$ to $\mathrm{D}$ & $\begin{array}{c}0.512 \\
(0.117)\end{array}$ & $\begin{array}{c}0.730 \\
(0.120)\end{array}$ & 378 & 100 \\
\hline All rated & $\begin{array}{c}0.135 \\
(0.006)\end{array}$ & $\begin{array}{c}0.277 \\
(0.002)\end{array}$ & 21,808 & 2,587 \\
\hline All unrated & $\begin{array}{c}0.276 \\
(0.003)\end{array}$ & $\begin{array}{c}0.258 \\
(0.002)\end{array}$ & 145,512 & 15,704 \\
\hline
\end{tabular}

empirical model to estimate adjustment speeds is the same as in the previous sections. The table compares SOA estimates from DPF and Blundell-Bond (1998) estimation.

As can be seen from Table 10, although both estimators yield an average SOA estimate of about $26 \%$ for the full sample of rated and unrated firms, estimates for the rating subsamples differ substantially between firm groups, and between estimators in particular. For example, for all rated firms, DPF estimation leads to an estimate of 0.135 versus 0.277 using Blundell-Bond (1998) ("All rated," Table 10). The corresponding half-lives of leverage shocks translate into 4.8 years (DPF) versus 2.1 years (Blundell-Bond), which essentially implies slow versus fast adjustment. The Blundell-Bond estimator basically estimates a flat and fast adjustment pattern across all rating categories with a peak at the category with highest default risk ("CCC+ to D"). In contrast, the DPF estimator indicates a U-shaped adjustment pattern that estimates only fast adjustment for the rating categories with the lowest ("AAA to AA-") and highest default risk ("CCC+ to D").

\section{Conclusion}

In this study, we use Monte Carlo simulations and resampling experiments to demonstrate that even the estimators suggested in the most recent capital structure

distressed in later periods (and vice versa). Nonetheless, all estimators will be subject to the same selection bias, and relying on long-term averages will bias the results against finding differences in the SOA. 
literature (e.g., the Blundell-Bond (1998) GMM estimator, the long difference estimator, or the LSDVC estimator) yield biased estimates of the speed of adjustment toward target capital structure. These estimators do not account for the fact that debt ratios are fractional (i.e., bounded between $0 \%$ and 100\%).

We suggest a new estimator, which is nearly unbiased and consistent in the context of unbalanced dynamic panel data with a fractional dependent variable (the DPF estimator), and we test its statistical properties in the context of capital structure data. We find that the DPF estimator is unbiased (or the least-biased estimator available) for typical corporate finance data. Furthermore, it is robust against common types of model misspecification, although it is a maximum likelihood estimator that rests on normality assumptions for regression error terms and the fixed effects distribution.

Most of our results, such as the "mechanical mean reversion" problem of standard estimators due to censoring, do not only hold in capital structure research but are also relevant in other areas of corporate finance such as dividend policy and corporate cash holdings. The DPF estimator can be applied in these situations as well. Moreover, since it is basically an extended doubly censored Tobit model, it is easily implementable in standard econometric software packages.

Based on our results from Monte Carlo simulations, we encourage researchers in empirical corporate finance not to rely on easy work-arounds for fractional dependent variables, such as omitting boundary values or extensive winsorizing. These work-arounds do not necessarily mitigate the bias of nonfractional estimators. Finally, even if results from a standard estimator (like BlundellBond (1998)) are similar to an unbiased estimator (like the DPF) in some samples, this does not imply that the bias due to censoring can be ignored in other realworld settings. Estimation results for subsamples of such data can nevertheless be very different.

\section{References}

Alti, A. "How Persistent Is the Impact of Market Timing on Capital Structure?" Journal of Finance, 61 (2006), 1681-1710.

Arellano, M., and S. Bond. "Some Tests of Specification for Panel Data: Monte Carlo Evidence and an Application to Employment Equations." Review of Economic Studies, 58 (1991), 277-297.

Baker, M., and J. Wurgler. "Market Timing and Capital Structure." Journal of Finance, 57 (2002), $1-32$.

Baltagi, B. H. Econometric Analysis of Panel Data. West Sussex, England: John Wiley \& Sons (2005).

Blundell, R., and S. Bond. "Initial Conditions and Moment Restrictions in Dynamic Panel Data Models." Journal of Econometrics, 87 (1998), 115-143.

Bollerslev, T., and J. M. Wooldridge. "Quasi-Maximum Likelihood Estimation and Inference in Dynamic Models with Time-Varying Covariances.” Econometric Reviews, 11 (1992), 143-172.

Bruno, G. S. F. "Approximating the Bias of the LSDVC Estimator for Dynamic Unbalanced Panel Data Models." Economics Letters, 87 (2005a), 361-366.

Bruno, G. S. F. "Estimation and Inference in Dynamic Unbalanced Panel-Data Models with a Small Number of Individuals." Stata Journal, 5 (2005b), 473-500.

Chamberlain, G. "Analysis of Covariance with Qualitative Data." Review of Economic Studies, 47 (1980), 225-238.

Chang, X., and S. Dasgupta. "Target Behavior and Financing: How Conclusive Is the Evidence?" Journal of Finance, 64 (2009), 1767-1796.

Dittmar, A., and A. Thakor. "Why Do Firms Issue Equity?" Journal of Finance, 62 (2007), 1-54.

Elsas, R., and D. Florysiak. "Heterogeneity in the Speed of Adjustment toward Target Leverage." International Review of Finance, 11 (2011), 181-211. 
Fama, E. F., and K. R. French. "Industry Costs of Equity.” Journal of Financial Economics, 43 (1997), 153-193.

Fama, E. F., and K. R. French. "Testing Trade-Off and Pecking Order Predictions about Dividends and Debt." Review of Financial Studies, 15 (2002), 1-33.

Fama, E. F., and J. D. MacBeth. "Risk, Return, and Equilibrium: Empirical Tests." Journal of Political Economy, 81 (1973), 607-636.

Faulkender, M.; M. J. Flannery; K. W. Hankins; and J. M. Smith. "Cash Flows and Leverage Adjustments.” Journal of Financial Economics, 103 (2012), 632-646.

Fischer, E. O.; R. Heinkel; and J. Zechner. "Dynamic Capital Structure Choice: Theory and Tests." Journal of Finance, 44 (1989), 19-40.

Flannery, M. J., and K. W. Hankins. "Estimating Dynamic Panel Models in Corporate Finance.” Journal of Corporate Finance, 19 (2013), 1-19.

Flannery, M. J., and K. P. Rangan. "Partial Adjustment toward Target Capital Structures." Journal of Financial Economics, 79 (2006), 469-506.

Frank, M. Z., and V. K. Goyal. "Tradeoff and Pecking Order Theories of Debt." In Handbook of Empirical Corporate Finance, Vol. 2, B. E. Eckbo, ed. Amsterdam: Elsevier Science (2008), 135202.

Graham, J. R., and R. C. Harvey. "The Theory and Practice of Corporate Finance: Evidence from the Field.” Journal of Financial Economics, 60 (2001), 187-243.

Graham, J. R., and M. T. Leary. "A Review of Empirical Capital Structure Research and Directions for the Future.” Annual Review of Financial Economics, 3 (2011), 309-345.

Greene, W. H. Econometric Analysis, 7th ed. Upper Saddle River, NJ: Prentice-Hall (2011).

Hahn, J.; J. Hausman; and G. Kuersteiner. "Long Difference Instrumental Variables Estimation for Dynamic Panel Models with Fixed Effects.” Journal of Econometrics, 140 (2007), 574-617.

Hovakimian, A., and G. Li. "Is the Partial Adjustment Model a Useful Tool for Capital Structure Research?" Review of Finance, 16 (2012), 733-754.

Huang, R., and J. R. Ritter. "Testing Theories of Capital Structure and Estimating the Speed of Adjustment." Journal of Financial and Quantitative Analysis, 44 (2009), 237-271.

Iliev, P., and I. Welch. "Reconciling Estimates of the Speed of Adjustment of Leverage Ratios." Working Paper, Pennsylvania State University (2010).

Kayhan, A., and S. Titman. "Firms' Histories and Their Capital Structures." Journal of Financial Economics, 83 (2007), 1-32.

Kisgen, D. J. “Credit Ratings and Capital Structure.” Journal of Finance, 61 (2006), 1035-1073.

Kisgen, D. J. "Do Firms Target Credit Ratings or Leverage Levels?" Journal of Financial and Quantitative Analysis, 44 (2009), 1323-1344.

Kiviet, J. F. "On Bias, Inconsistency, and Efficiency of Various Estimators in Dynamic Panel Data Models.” Journal of Econometrics, 68 (1995), 53-78.

Leary, M. T., and M. R. Roberts. "Do Firms Rebalance Their Capital Structures?" Journal of Finance, 60 (2005), 2575-2619.

Lemmon, M. L.; M. R. Roberts; and J. F. Zender. "Back to the Beginning: Persistence and the CrossSection of Corporate Capital Structure.” Journal of Finance, 63 (2008), 1575-1608.

Lockhart, G. B. "Adjusting to Target Capital Structure: The Effect of Credit Lines." Working Paper, University of Nebraska-Lincoln (2010).

Loudermilk, M. S. "Estimation of Fractional Dependent Variables in Dynamic Panel Data Models with an Application to Firm Dividend Policy." Journal of Business and Economic Statistics, 25 (2007), 462-472.

Mundlak, Y. "On the Pooling of Time Series and Cross Section Data." Econometrica, 46 (1978), 69-85.

Nickell, S. "Biases in Dynamic Models with Fixed Effects." Econometrica, 49 (1981), 1417-1426.

Oztekin, O., and M. J. Flannery. "Institutional Determinants of Capital Structure Adjustment Speeds." Journal of Financial Economics, 103 (2012), 88-112.

Papke, L. E., and J. M. Wooldridge. "Panel Data Methods for Fractional Response Variables with an Application to Test Pass Rates.” Journal of Econometrics, 145 (2008), 121-133.

Strebulaev, I. A. "Do Tests of Capital Structure Theory Mean What They Say?" Journal of Finance, 62 (2007), 1747-1787.

Titman, S., and S. Tsyplakov. “A Dynamic Model of Optimal Capital Structure.” Review of Finance, 11 (2007), 401-451.

Welch, I. “Capital Structure and Stock Returns.” Journal of Political Economy, 112 (2004), 106-131.

Welch, I. "Two Common Problems in Capital Structure Research: The Financial-Debt-to-Asset Ratio and Issuing Activity versus Leverage Changes.” International Review of Finance, 11 (2011), 1-17.

Wooldridge, J. M. "Fixed-Effects and Related Estimators for Correlated Random-Coefficient and Treatment-Effect Panel Data Models.” Review of Economics and Statistics, 87 (2005), 385-390. 